\title{
Undrained capacity of surface foundations with zero-tension interface under planar V-H-M loading
}

\author{
Z. Shen ${ }^{\mathrm{a}}, \mathrm{X}$. Feng ${ }^{\mathrm{b}, *}$ and S. Gourvenec ${ }^{\mathrm{b}}$
}

Published in Computers in Geotechnics, 73: 47-57

http://dx.doi.org/10.1016/j.compgeo.2015.11.024

\section{Zhichao SHEN}

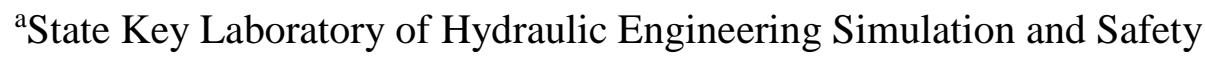

Tianjin University

92 Weijin Road, Nankai District

Tianjin, 300072

China

Visiting scholar at Centre for Offshore Foundation Systems, University of Western Australia Mobile phone: +86 15822433727

Email: shenzhch@163.com

\section{Xiaowei FENG (corresponding author)}

${ }^{\mathrm{b} C e n t r e}$ for Offshore Foundation Systems, a node of the ARC Centre of Excellence for Geotechnical Science and Engineering

University of Western Australia

35 Stirling Highway, Crawley

Perth, WA 6009

Australia

Tel: +61 864882473

Fax: +61 864881044

Email: xiaowei.feng@uwa.edu.au

\section{Susan GOURVENEC}

${ }^{\mathrm{b} C e n t r e}$ for Offshore Foundation Systems, a node of the ARC Centre of Excellence for Geotechnical Science and Engineering

University of Western Australia

Tel: +61 864883094

Email: susan.gourvenec@uwa.edu.au

No. of words: 4649 (without abstract and references)

No. of tables: 3

No. of figures: 15 


\title{
Undrained capacity of surface foundations with zero-tension interface
}

\section{under planar V-H-M loading}

\author{
Z. Shen ${ }^{\mathrm{a}}$, X. Feng ${ }^{\mathrm{b}, *}$ and S. Gourvenec ${ }^{\mathrm{b}}$
}

\begin{abstract}
Undrained capacity of strip and circular surface foundations with a zero-tension interface on a deposit with varying degrees of strength heterogeneity is investigated by finite element analyses. The method for simulating the zero-tension interface numerically is validated. Failure envelopes for strip and circular surface foundations under undrained planar V-H-M loading are presented and compared with predictions from traditional bearing capacity theory. Similar capacity is predicted with both methods in V-H and V-M loading space while the traditional bearing capacity approach under-estimates the V-H-M capacity derived from the numerical analyses due to superposition of solutions for load inclination and eccentricity not adequately capturing the true soil response. An approximating expression is proposed to describe the shape of normalised V-H-M failure envelopes for strip and circular foundations with a zero-tension interface. The unifying expression enables implementation in an automated calculation tool resulting in essentially instantaneous generation of combined loading failure envelopes and optimization of a foundation design as a function of foundation size or material factor. In contrast, the traditional bearing capacity theory approach or direct numerical analyses for a given scenario requires a raft of ad-hoc analyses covering a range of input variables in order to obtain the 'best' design.
\end{abstract}

Keywords: zero-tension interfaces; bearing capacity; footings/foundations; numerical modelling; offshore engineering 


\section{Introduction}

Capacity of shallow foundations under combined loading is of particular interest in offshore geotechnical design as environmental forces, such as wave and wind, and operational forces impose significant lateral loads and moments to foundations supporting offshore facilities or seabed structures. Combined loading of shallow foundations is also relevant for onshore geotechnical design, particularly for relatively light-weight structures, that are subject to significant environmental loading, or horizontal operational loading, such as wind turbines, transmission towers and masts. The traditional solution to load-carrying capacity of shallow foundations under combined loading is based on classical bearing capacity theory for the uniaxial vertical capacity of an infinitely long surface strip foundation resting on a uniform plastic half-space, augmented with modification factors to account for non-verticality of load, foundation geometry, embedment and soil strength heterogeneity (e.g. API [1]; ISO [2]; Eurocode 7 [3]). While the traditional bearing capacity theory approach is simple in its linear formulation, it is unwieldy for automated iteration for optimization of routine design, and can be inaccurate due to the simple linear superposition of the various modification factors and separate solutions for load inclination and eccentricity [4].

The 'failure envelope' approach has experienced increasing acceptance for prediction of the undrained ultimate limit states for shallow foundations under combined loading. Key advantages of the approach are (1) explicit consideration of the independent load components, foundation geometry and soil conditions (rather than superposing modification factors), and (2) optimization of design output (e.g. foundation footprint or weight) as a function of any input variable through describing the normalised combined ultimate limit state with an approximating expression enabling automated calculation through a simple spreadsheet or scripting tool. 
Failure envelopes for shallow foundations of various geometries have been proposed from previous studies, but these mostly considered a fully bonded interface between the foundation and subsoil, i.e. able to transmit unlimited tension [5-9]. In practice, this tensile resistance can be mobilised in offshore environments through generation of negative excess pore pressure (i.e. suction relative to ambient pressure) between the underside of the foundation and soil under uplift or overturning moment. However, the reliability of under-base suction is conditional. Perforations of foundation base plates $[10,11]$, loss of sealing through a drainage or vent valve, or a vertical gap along a skirt-soil interface for skirted shallow foundations [12] can provide access to free water and lead to dissipation of suction at the underside of the foundation. Sparse literature is available for shallow foundations under general loading with an interface unable to sustain tension, often referred to as a 'zero-tension' interface. The 'effective area’ rule suggested by Meyerhof [13] to account for moment loading, based on the vertical bearing capacity of a reduced width foundation, has been widely accepted in geotechnical design. It is considered a useful hypothesis to account for possible detachment from the soil for a foundation with zero-tension interface by reducing the foundation width by twice-the-eccentricity to its 'effective width'. Salençon and Pecker [14] presented failure envelopes for a surface strip foundation with a zero-tension interface on uniform soil based on plasticity limit analysis. However, benefits of normality and convexity of the hypothesis of Drucker [15] were employed to describe the behaviour of the zero-tension interface. Houlsby and Puzrin [16] pointed out such an interface condition was not physically reasonable, since shear stress can apparently be sustained by the interface instantly after separation and separation is never accompanied by tangential movement. Further hypotheses have been proposed by Houlsby and Puzrin [16] based on the bound theorems of plasticity theory accounting for the violation of normality at the interface between the foundation and the soil. The 'apparent' lower-bound and upper-bound solutions were pursued using the notion of a 
'scaled foundation'. The effect of under-base suction on bearing capacity of strip foundations was investigated by Ukritchon et al. [17] using finite-element limit analysis and the proposed failure envelopes in V-H-M loading space for foundations with zero-tension interface fall far outside those derived by FEA presented by Gourvenec [4] and Taiebat and Carter [18] for the same boundary condition (see Figure 1). In the results presented by Ukritchon et al. [17], shear stress can apparently be transmitted by the interface even after contact breaking, which may be responsible for the asymmetry in the $\mathrm{V}-\mathrm{H}-\mathrm{M}$ failure envelope and the over-prediction for the load-carrying capacity.

Numerical results for failure envelopes of strip and circular foundations with a zero-tension interface that are available in the public domain are compared with predictions from traditional bearing capacity theory as adopted in industry recommended practice and based on the effective area principle, in Figure 1. Those numerical analyses with a zero-tension interface have mostly considered shallow foundations on deposits with homogeneous shear strength [4, 18]. However, many, especially, deep water seabeds, are characterised by undrained shear strength linearly increasing with depth. Bransby [19] examined failure envelopes for surface strip foundations with zero-tension interface on a soil with nonhomogeneous undrained shear strength, but only for the case of combined V-M loading. The effect of soil heterogeneity on general V-H-M capacity has not been investigated systematically.

In this paper, undrained load-carrying capacity of strip and circular foundations unable to sustain interface tension, resting on material with different degrees of strength heterogeneity is investigated with finite element analyses. First, a 'standard' approximate approach for simulating the zero-tension interface is validated by comparison with results from analyses with a user-defined true zero-tension interface subroutine for plane strain conditions. Failure envelopes are then presented in normalised load space and compared with predictions from 
traditional bearing capacity theory solutions and other numerical results for the same boundary conditions available in the public domain. An approximating algebraic expression is ultimately proposed to predict the load-carrying capacity of strip and circular foundations on soil as a function of degree of strength heterogeneity. The unifying expression can be conveniently implemented in an automated calculation tool to essentially instantaneously generate failure envelopes or optimize a particular geotechnical design as a function of foundation dimension or material factor.

\section{Finite element model}

\subsection{Geometry and mesh}

All the finite element analyses were carried out using the software ABAQUS [20]. The study has considered strip and circular foundations of width or diameter $D$, founded on the surface of the soil. The three-dimensional finite element mesh in Figure 2 represents a semicylindrical section through a diametrical plane of a circular foundation of diameter $D$. The mesh boundaries extend a distance of $3 D$ from the edge of foundation and $3 D$ beneath the foundation, sufficiently remote that the load-displacement response of the foundation is unaffected. Mesh nodes on the diametrical plane on the front face of the mesh and around the circumference were constrained to prevent out-of-plane displacement of the vertical boundaries, while the nodes at the base of the mesh were fully constrained in all three coordinate directions. The mesh shown in Figure 2 comprises 10912 eight-node, hybrid brick elements. Relatively fine discretisation was employed in the vicinity of the edges of the foundation and immediately below the foundation to accommodate localised kinematic mechanisms associated with failures. The mesh tie constraint available in ABAQUS was adopted to connect a fine mesh in the region close to the foundation to a coarser mesh in the far field. Mesh tie constraint allows for transition in mesh density so that a more time-efficient 
model can be established by avoiding identical mesh density throughout the whole soil domain.

The same geometry and mesh discretisation as shown in the front face of the threedimensional mesh were employed for the strip foundations.

\subsection{Material property}

The undrained material response of the soil was represented with a linear elastic perfectly plastic constitutive law obeying the Tresca failure criterion, and defined by the undrained Young's modulus $\left(E_{\mathrm{u}}\right)$ and Poisson's ratio $(v)$. The soil shear strength $\left(s_{\mathrm{u}}\right)$ was assumed to be uniform with depth or increase linearly with depth according to $s_{\mathrm{u}}=s_{\mathrm{u} 0}+k z$, where $s_{\mathrm{u} 0}$ is the shear strength at foundation base level and $k$ is the gradient of soil shear strength. The idealised soil and foundation conditions are shown in Figure 3. The degree of soil heterogeneity was defined as $\kappa=k D / s_{\mathrm{u} 0}$, ranging from 0 (homogeneous soil) to 10 in this study. The Young's modulus of soil varied together with shear strength, maintaining a constant modulus ratio $\left(E_{\mathrm{u}} / \mathrm{s}_{\mathrm{u}}\right)$ of 1000. A Poisson's ratio of $v=0.49$ was described for the constant volume response of soil under undrained conditions. The foundation was modelled as a weightless, rigid body, with a reference point (RP) located at the centroid of the foundation base.

\subsection{Interface conditions}

The loading and geometry of the detaching foundation is illustrated in Figure 4a. An inclined resultant force $P$ is acting on the foundation at an eccentricity of $e$ from the foundation centroid such that the foundation separates from the soil over a length of AA' on the trailing edge. Detachment occurs once the contact normal stress between the foundation and the soil, $\sigma_{\mathrm{n}}<0$, i.e. tension cannot be sustained. The velocity vectors $u$ marked in Figure $4 \mathrm{~b}$ and c represents the possible separation velocities on the soil-foundation interface, and the direction of velocity from the soil-foundation interface $\theta$ is determined as $\theta=\tan ^{-1}\left(\Delta d_{\mathrm{n}} / \Delta d_{\mathrm{t}}\right)$, where 
$\Delta d_{\mathrm{n}}$ and $\Delta d_{\mathrm{t}}$ are the increments in the relative positions in the normal and tangential direction between the two contacting surfaces, respectively. The velocities parallel to the interface of A'B (i.e. $\theta=0^{\circ}$ ) where the contact is closed, imply sliding across the foundation base governs failure. After separation, the velocities, $u$, form an angle, $\theta$, from the interface AA' (i.e. $\theta>0^{\circ}$ ) where the contact breaking occurs. The point of $\mathrm{A}^{\prime}$ is at the instant of separation, the foundation detaches from the soil and the directions of the velocities might be parallel to the interface, perpendicular or fall in between.

The behaviour of the zero-tension interface can be taken as a limiting case of a non-dilative frictional interface with an angle of friction approaching $90^{\circ}$ [16]. A yield surface for such a frictional interface is illustrated in Figure $4 \mathrm{~b}$ and can be conveniently defined in ABAQUS by the Coulomb friction interface which is implemented using the penalty method. In this paper, a coefficient of friction $\mu=20$ (i.e. the equivalent friction angle of $\varphi=\tan ^{-1} 20, \sim 87.1^{\circ}$ ) was adopted to simulate the interface behaviour shown in Figure 4b. The surface-to-surface contact using the small-sliding tracking approach was employed to model the soil-foundation interaction. The advantage of this method is that the coding for the interfacial constitutive behaviour can be avoided, which would be heavy for three dimensional conditions.

In order to validate the aforementioned approach for simulating the zero-tension interface, the ideally normal and tangential behaviour of the zero-tension interface, as shown in Figure 4c, was programmed as an ABAQUS user subroutine through UINTER, for plane strain conditions. Variables including relative position in the normal direction, $d_{\mathrm{n}}$ and tangential direction $d_{\mathrm{t}}$, and the corresponding increments in the relative positions between the two contacting surfaces, $\Delta d_{\mathrm{n}}$ and $\Delta d_{\mathrm{t}}$ were passed into UINTER by ABAQUS Standard. The relationship between $d_{\mathrm{n}}$ and the contact pressure, $\sigma_{\mathrm{n}}$ is determined by Equation (1), which defines the normal behaviour of the interface when the relative contact displacement in the normal direction, i.e. the clearance, is less than a tolerance of $10^{-10}$. 
$\sigma_{\mathrm{n}}=\mathrm{k}_{\mathrm{n}} \mathrm{d}_{\mathrm{n}}$

where $k_{\mathrm{n}}$ is the elastic normal stiffness.

The relationship of $d_{\mathrm{t}}$ and the shear stress, $\tau$, reflecting the tangential behaviour, is given by

$$
\left\{\begin{array}{l}
\tau=k_{s} d_{t}=\frac{\tau_{\text {lim }}}{\gamma_{\text {crit }}} \mathrm{d}_{\mathrm{t}}, \text { if }\left|\mathrm{d}_{\mathrm{t}}\right| \leq \gamma_{\text {crit }} \text { (elastic slip) } \\
\tau=\tau_{\lim } \frac{\mathrm{d}_{\mathrm{t}}}{\left|\mathrm{d}_{\mathrm{t}}\right|}, \text { if }\left|\mathrm{d}_{\mathrm{t}}\right|>\gamma_{\text {crit }} \text { (plastic slip) }
\end{array}\right.
$$

where $\mathrm{k}_{\mathrm{s}}$ is the elastic shear stiffness, $\tau_{\mathrm{lim}}$ is the critical shear stress defined as the undrained soil shear strength at the foundation base level, $s_{\mathrm{u} 0}$, and $\gamma_{\text {crit }}$ is the allowable maximum elastic slip for relative motion of the contacting surfaces, set to $0.5 \%$ the characteristic contact surface length, $l_{\mathrm{i}}$. ABAQUS scans all of the facets of all the soil surfaces that are in contact with the foundation when calculating $l_{\mathrm{i}}$. The separation of the foundation and the soil (i.e. contact breaking) was identified when the clearance in the normal direction was greater than the adopted tolerance due to uplift or overturning moment. Immediately after separation, no stress can be sustained by the interface. The normal and shear traction at the contact breaking point will instantly jump to point $\mathrm{O}$ (in Figure 4c), i.e. $\sigma_{\mathrm{n}}=0$ and $\tau=0$, irrespective of the position of the contact stress point immediately before separation. The unbalanced stresses that may exist at this stage on the interface will be applied to the adjacent nodes and redistributed across the FE system to maintain equilibrium in the following increment. The flowchart for the implementation of the user subroutine is illustrated in Figure 5. The code programmed in UINTER is provided in the Appendix.

\subsection{Loading path}

Displacement controlled probe tests and sideswipe tests were employed to identify the failure envelopes in V-H and V-M loading space. For general V-H-M loading, a constant vertical load, expressed as a proportion of the ultimate vertical capacity, was first imposed and the 
horizontal load and moment were then applied as a series of displacement probes to detect each failure envelope [7].

\subsection{Sign convention and nomenclature}

The sign convention for loads used in this study, as shown in Figure 3, follows that suggested by Butterfield et al. [21]. The notation adopted for loads is summarized in Table 1 . The ultimate loads are the pure load-carrying capacity for horizontal and vertical loads in the absence of other loading. The ultimate moment is referred to as the maximum available moment capacity under non-zero vertical load, since no overturning moment can be sustained by a foundation with a zero-tension interface in the absence of vertical load.

\section{Results}

\subsection{Validation}

The dimensionless ultimate vertical loads of a strip and circular foundation for varying degrees of soil strength heterogeneity are summarized in Table 2 along with documented values in the public domain. The FEA under-predict the exact solutions for circular foundations by $3 \%$ for uniform soil $(\kappa=0)$, to below $1 \%$ for the case of $\kappa=10$ [22]. The under-prediction of the vertical bearing capacity by FEA is attribute to the built-in ABAQUS implementation of Tresca, using a von Mises surface for the plastic potential [23, 24]. For a surface foundation resting on a deposit with uniform or linearly increasing shear strength with depth, the ultimate horizontal capacity is theoretically the product of the soil shear strength at foundation level, $s_{\mathrm{u} 0}$, and the foundation bearing area, $A$, irrespective of foundation geometry and the degree of soil strength heterogeneity. The exact solution of the ultimate horizontal capacity of the strip and circular foundations is over-predicted by approximately $2 \%$ for the uniform soil (i.e. $\kappa=0$ ), and up to $4 \%$ for the soil profile with $\kappa=10$. The dimensionless moment capacity and the corresponding vertical load at which the ultimate moment is mobilised are presented in Table 3. The FE results of the ultimate moment are slightly higher 
than the traditional method solutions, but within 5\% for all the cases, whereas the discrepancy in the normalised vertical loads at which the moment capacity is mobilised is negligible. The ultimate moment capacity of the strip and circular foundations is generally mobilised as the vertical load approaches approximately $50 \%$ of $V_{\text {ult, }}$ reflecting the implication of the effective area method and solution presented by Taiebat and Carter [25] for circular foundation geometry.

Figure 6 compares the $\mathrm{V}-\mathrm{H}-\mathrm{M}$ failure envelopes of strip foundations with a zero-tension interface on uniform soil defined by the Coulomb friction and the interfacial constitutive behaviour programmed in user subroutine UINTER with other published results for the same boundary conditions. The interfacial constitutive behaviour used in this study is shown in Figure 4. Results derived from the two methods show good agreement, reflecting that the behaviour of a zero-tension interface can be simulated by Coulomb friction with the angle of friction approaching $90^{\circ}$. Failure envelopes derived from this study agree well with the expression proposed by Gourvenec [4], showing distinct separation from the results by Ukritchon et al. [17], for the reasons described in the Introduction (Figure 6). Current numerical results of the undrained $\mathrm{V}-\mathrm{H}-\mathrm{M}$ failure envelopes for circular foundations with zero-tension interface on a homogeneous deposit are also shown together with those obtained by Taiebat and Carter [18] (Figure 7).

Agreement with other published data for plane strain and three-dimensional cases further validates that a zero-tension soil-foundation interface can be simulated by the simple Coulomb friction with the angle of friction approaching $90^{\circ}$. In the following numerical analyses, a zero-tension interface is simulated by Coulomb friction with a friction angle of $87.1^{\circ}$. 


\subsection{V-H loading space $(M=0)$}

Equation (3) has been historically proposed as a simple curve fit to Green’s original solution to consider load inclination [26]

$v=0.5+0.5 \sqrt{1-h}$

where

$h=1$ for $v \leq 0.5$

Figure 8 compares failure envelopes obtained by FE results with predictions from Equation (3). FE results agree well with the traditional solution for strip foundations on uniform strength soil, the conditions for which it was derived, but the envelopes diverge increasingly with increasing degree of soil strength heterogeneity for both strip and circular foundations showing that simple scaling of the envelope by the ultimate vertical and horizontal limit states, as described in Equation (3), does not capture accurately the effect of strength heterogeneity on V-H capacity.

\subsection{V-M loading space $(H=0)$}

Figure 9 and Figure 10 show V-M failure envelopes in terms of dimensionless loads and normalised loads for strip and circular foundations on deposits with different degrees of soil strength heterogeneity. Results derived from the traditional method based on the effective area rule generally agree with the lower-bound approximation by Bransby [19] using the concept of a 'scaled foundation' [16], and fall inside the current numerical results for strip foundations for all soil conditions (Figure 9a). Agreement between the traditional method and FEA results for circular foundations (Figure 10) is also good, with the slight disparity attributable to the under prediction of the uniaxial vertical capacity predicted by the FEA as explained in section 3.1. If ABAQUS could predict the vertical bearing capacity of circular foundation accurately, the results of traditional method would lie entirely inside the failure envelopes derived from the FE analyses. (Figure 10a). The numerical results generally agree 
well with those predicted by the effective area method in normalised load space for all foundation geometry and soil conditions. The normalised V-M failure envelopes for strip foundations on heterogeneous deposits $(2 \leq \kappa \leq 10)$ fall in a tight band although slightly offset to the left of centre compared with the case for homogenous soil strength, $\kappa=0$.

Undrained normalised V-M failure envelopes for strip foundations on homogenous deposits have been described by a parabolic function [4],

$m=4\left(v-v^{2}\right)$

This expression is shown to accurately describe the shape of the normalised failure envelopes for strip and circular foundations for a range of soil strength heterogeneity. The failure envelope given by Equation (4) is shown in Figure 9b and Figure 10b against those derived from the traditional effective area method and finite element analyses.

Alternatively, V-M failure envelopes can be represented with the normalised vertical bearing capacity in regard to varying load eccentricity, as shown in Figure 11. From this figure it is clear that a linear relationship between vertical load mobilisation and load eccentricity is achieved only for the case of a strip foundation on a uniform strength deposit. The relationship becomes increasingly non-linear with increasing degree of soil strength heterogeneity for both strip and circular foundation geometry.

\subsection{V-H-M loading space}

Figure 12 and Figure 13 show failure envelopes in normalised H-M loading space at intervals of vertical load mobilization for strip and circular foundations respectively. Failure envelopes derived from the traditional method predict lower capacity in comparison with the finite element results. Further, the failure envelopes derived from the traditional method are symmetrical for all levels of soil strength heterogeneity and relative vertical load because of the assumption that the response of the foundation is independent of the directions of the coupled H-M loading. In contrast, failure envelopes obtained from finite element results 
exhibit asymmetry as the degree of soil strength heterogeneity and level of relative vertical load increases due to the interaction of horizontal load and moment. For the cases of $H$ and $M$ being applied in the same direction (i.e. left-to-right and clockwise, $+\mathrm{H}+\mathrm{M}$, or vice-versa, $-\mathrm{H}$ M), the direction of the shear stress around the leading edge of the foundation reverses (i.e. opposite with the direction of $H$ ) because of the rotation of the foundation. Therefore, the mobilised horizontal resistance is reduced. This phenomenon becomes more pronounced for higher levels of vertical load mobilisation and degree of soil strength heterogeneity.

The normalised failure envelopes of circular foundations expand with increasing shear strength heterogeneity for all levels of vertical load mobilisation (Figure 13). The same is observed for strip foundations for vertical load mobilisations $v \leq 0.5$ (Figure 12a and b). In contrast, for $v>0.5$, the normalised H-M failure envelopes for the case of uniform soil strength $(\kappa=0)$ lie outermost, particularly when the horizontal load and moment act in the same direction (Figure 12c). A possible reason for this peculiar phenomenon is illustrated below.

According to the effective area method [13],

$$
\frac{m}{v}=\frac{e / D}{N_{\mathrm{cm}} / N_{\mathrm{cv}}}
$$

where $e$ is the load eccentricity, $N_{\mathrm{cm}}=M_{\mathrm{ult}} / A D s_{\mathrm{u} 0}$ and $N_{\mathrm{cv}}=V_{\mathrm{ult}} / A s_{\mathrm{u} 0}$.

Figure 14 shows an example of the trends of $m / v, e / D$ and $N_{\mathrm{cm}} / N_{\mathrm{cv}}$ with varying degree of soil strength heterogeneity for strip and circular foundations under $v=0.75$. For circular foundations, the curve for the ratio of $e / D$ is approximately parallel to that of $N_{\mathrm{cm}} / N_{\mathrm{cv}}$ for all soil strength heterogeneity. For strip foundations, the two curves intersect for uniform soil strength and become approximately parallel as the degree of heterogeneity increases. As a result, the value of $m / v$ for circular foundations according to Equation (5) maintains at a stable 
value of $\sim 0.95$ independent of strength heterogeneity, whereas $m / v$ reduces from unity to 0.96 as the degree of soil heterogeneity, $\kappa$, increases from 0 to 2 for strip foundations.

Figure 15 shows total displacement vectors corresponding to the points A, B and C $(h / m=1)$ indicated in Figure 12 for a strip foundation on uniform soil under combined V-H-M loading. Figure 15 illustrates the extent of loss of contact or lift-off of the foundation from the soil as a function of the relative vertical load. To present the gapping clearly, a smaller scaling factor was used for the deformed domain under higher levels of vertical load mobilisation, since larger local displacement was found in vicinity of the foundation under larger vertical load. The adopted scaling factors have no influence on the relative length of the gap to the foundation width. The gap decreases with increasing magnitude of vertical load as would be expected.

A circular ellipse expression was proposed by Gourvenec [4] to approximate the shape of the undrained normalised V-H-M failure envelope for square, rectangular and strip foundations with a zero-tension interface resting on a homogeneous deposit (as shown in Figure 6):

$\left(\frac{h}{h^{*}}\right)^{2}+\left(\frac{m}{m^{*}}\right)^{2}=1$

where $h^{*}$ and $m^{*}$ define the shape of the normalised interaction in V-H and V-M planes respectively. $h^{*}$ is rearranged from Equation (3) and $m^{*}$ is directly given by Equation (4)

$h^{*}=1-4(v-0.5)^{2}, v>0.5$

$h^{*}=1, v \leq 0.5$

and

$m^{*}=4\left(v-v^{2}\right)$

Better fit to the FEA results can be achieved by adjusting the general circular ellipse of Equation (6):

$\left(\frac{h}{h^{*}}\right)^{2}+\left(\frac{m}{m^{*}}\right)^{q}=1$ 
where $h^{*}$ and $m^{*}$ follow definitions in Equations (7) and (8) while $q=1.5$ for circular and strip foundations. For the strip foundation geometry and cases of high vertical load mobilisation, $v>0.5, q=1.0$ provides a more conservative fit.

Failure envelopes predicted by the approximating expression given in Equation (9) are compared with the results from the traditional method and finite element analyses in Figure 12 and Figure 13. The symmetrical elliptical failure envelope defined by Equation (9) does not capture the asymmetry observed in the FEA results with increasing soil strength heterogeneity but nonetheless, generally provides a lower limit to the finite element results and enables greater load capacity to be relied on compared with traditional bearing capacity theory. An asymmetric elliptical expression cannot capture the observed asymmetry since the shape of the failure envelope only varies in one pair of quadrants $(-\mathrm{H}+\mathrm{M}$ and $+\mathrm{H}-\mathrm{M})$. The effect of the soil strength heterogeneity has no effect on the shape of the normalised failure envelope when $\mathrm{H}$ and $\mathrm{M}$ act in the same direction (i.e. $+\mathrm{H}+\mathrm{M}$ or $-\mathrm{H}-\mathrm{M}$ ). Since in many field conditions, moment derives from an eccentrically applied horizontal load, these two components typically act in the same direction, and as such the simple symmetrical elliptical expression is considered appropriate and pragmatic as a single unifying expression. The key benefit of the unified fitting expression lies in the ability to essentially instantaneously generate V-H-M failure envelopes and optimize foundation sizing based on constraint of any input variable.

\section{Conclusions}

Undrained failure envelopes were investigated for strip and circular surface foundations with a zero-tension interface using finite element analyses. A conveniently available frictional model and user-defined interfacial constitutive model were employed to simulate the behaviour of the zero-tension interface validating that a zero-tension interface can be 
modelled efficiently by Coulomb frictional contact with an angle of friction approaching $90^{\circ}$. Caution should be exercised when programming a user subroutine for zero-tension interface or selecting an 'off the shelf' zero-tension interface formulation, that interface shear stresses are appropriately considered following separation. Immediately after separation, no stress can be sustained by the interface and unbalanced stresses must be redistributed across the system to maintain equilibrium.

The V-H failure envelopes derived from FE results are shown to agree well with traditional bearing capacity method solutions for a strip foundation on uniform strength soil, but diverge with increasing degree of soil heterogeneity for both strip and circular foundations. The V-M failure envelopes obtained from FE analysis are very close to and marginally higher than the effective area method for the bearing capacity of eccentrically loaded strip and circular foundations on soil with varying degrees of soil heterogeneity. Failure envelopes in normalised V-M loading space are generally symmetrical with respect to $V / V_{\text {ult }}=0.5$ and shown to be well predicted by a parabolic function.

The traditional bearing capacity theory approach of superposing $\mathrm{V}-\mathrm{H}$ and $\mathrm{V}-\mathrm{M}$ solutions to represent combined V-H-M conditions is shown to be conservative. Asymmetry of the V-HM failure envelopes becomes more pronounced with increasing vertical load mobilisation and degree of soil strength heterogeneity. An approximating expression is proposed to describe the normalised V-H-M failure envelopes for strip and circular foundations with a zero-tension interface.

The proposed unifying expression enables essentially instantaneous generation of combined loading failure envelopes and optimization of a geotechnical foundation design as a function of foundation size or material factor through implementation in a simple spreadsheet or scripting tool. The proposed solution is of particular interest for design of perforated or vented offshore foundations as passive suctions cannot be developed to provide transient tensile 
interface resistance or for onshore design of relatively light-weight structures subjected to significant H-M loading, such as wind turbines, transmission towers or masts.

\section{Acknowledgements}

This work forms part of the activities of the Centre for Offshore Foundation Systems (COFS), currently supported as a node of the Australian Research Council Centre of Excellence for Geotechnical Science and Engineering and as a Centre of Excellence by the Lloyd's Register Foundation. Lloyd's Register Foundation helps to protect life and property by supporting engineering-related education, public engagement and the application of research. The work presented in this paper is supported through Australian Research Council Discovery Project Grant DP140100684. The first author worked on the research project presented in this paper while a visiting scholar at the Centre for Offshore Foundation Systems (COFS), UWA, supported through a China Scholarship Council (CSC) scholarship. This support is gratefully acknowledged.

\section{Appendix}

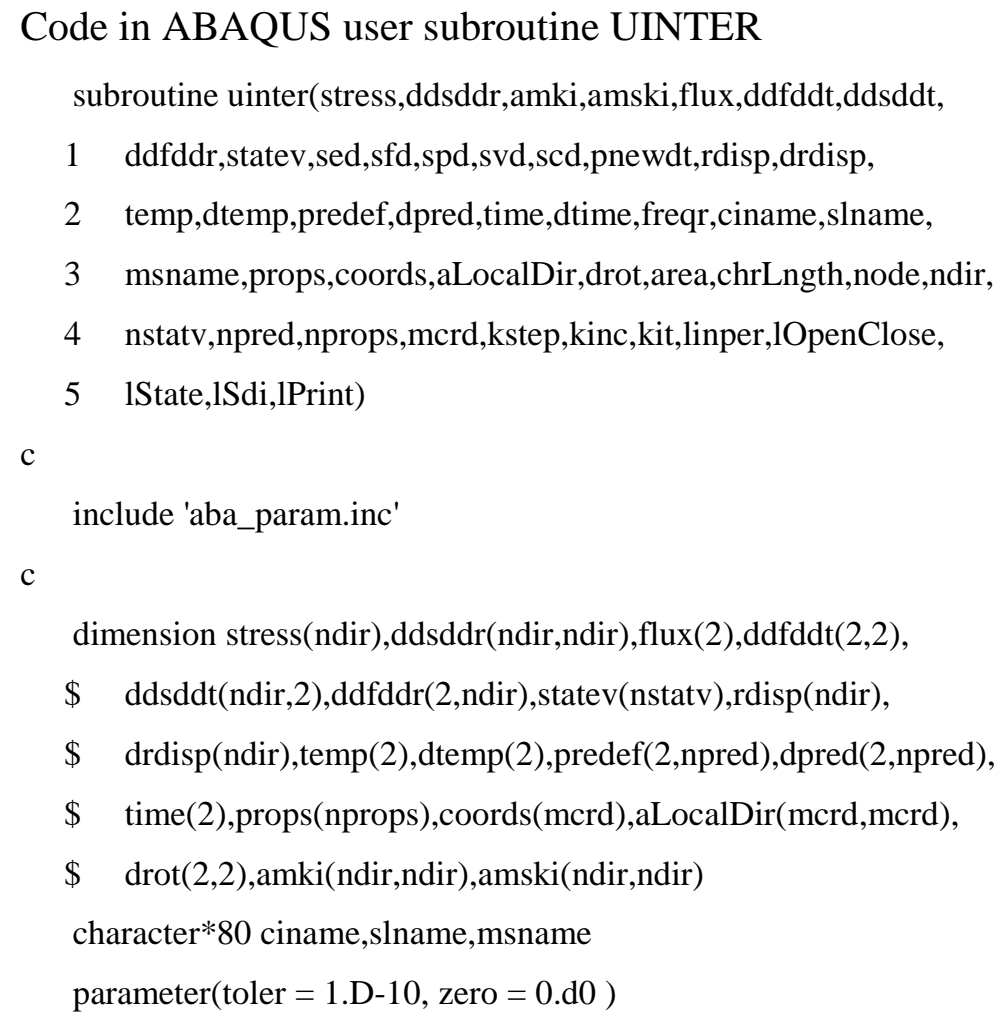


C

c User defined interfacial constitutive behaviour with penalty method.

C

C

c Local variables

c

$\mathrm{dp}=$ zero

taucrit $=$ zero

stiff $=$ zero

tauelas $=$ zero

gtplusdt $=$ zero

gcrit $=0.005^{*}$ chrlngth

C

c chrlngth is characteristic contact surface face dimension

C

c material properties

C

$$
\mathrm{su}=\operatorname{props}(1)
$$

$\mathrm{Eu}=1.0 \mathrm{D} 3 * \mathrm{su}$

C

c solution-dependent state variables

c statev(1) is elastic slip

$\mathrm{dn}=\operatorname{rdisp}(1)$

if ( $\mathrm{dn}$.ge. -toler) then

lopenclose $=1$ ! indicate contact is close

c compute normal stress

C

ekbar $=1.0 \mathrm{D} 5 * \mathrm{Eu} \quad !$ modulus in the normal direction

$\mathrm{dp}=\operatorname{ekbar}{ }^{*} \operatorname{drdisp}(1)$ ! incremental normal stress

$\operatorname{stress}(1)=\operatorname{stress}(1)+\mathrm{dp}$

taucrit $=\mathrm{su}$

stiff $=$ taucrit/gcrit

c compute shear stress assuming increment is elastic

C

tauelas $=\operatorname{stiff} *(\operatorname{statev}(1)+\operatorname{drdisp}(2))$

C

c check whether slip is "elastic" or "plastic" 
C

if ( abs(tauelas) .lt. taucrit) then

C

c slip is "elastic"

C

$$
\begin{aligned}
& \operatorname{stress}(2)=\text { tauelas } \\
& \operatorname{statev}(1)=\operatorname{statev}(1)+\operatorname{drdisp}(2)
\end{aligned}
$$

C

c Jacobian

C

$$
\begin{aligned}
& \text { ddsddr(1,1) = ekbar } \\
& \text { ddsddr(2,1) = zero } \\
& \text { ddsddr(2,2) = stiff } \\
& \text { ddsddr }(1,2)=\text { zero }
\end{aligned}
$$

else

C

c slip is "plastic"

C

$$
\begin{aligned}
& \text { gtplusdt }=\operatorname{rdisp}(2) \\
& \operatorname{stress}(2)=\text { gtplusdt*taucrit/abs(gtplusdt) } \\
& \operatorname{statev(1)}=\operatorname{stress}(2) / \text { stiff }
\end{aligned}
$$

C

c Jacobian

C

$$
\begin{aligned}
& \text { ddsddr(1,1) = ekbar } \\
& \text { ddsddr(2,1) = zero } \\
& \text { ddsddr(2,2) = zero } \\
& \text { ddsddr(1,2) = zero }
\end{aligned}
$$

end if

else

lopenclose $=0$ ! indicate contact is open

$\operatorname{stress}(1)=$ zero

$\operatorname{stress}(2)=$ zero

$\operatorname{statev}(1)=$ zero

end if

return

end

\section{References}


[1] American Petroleum Institute. Recommended practice 2GEO geotechnical and foundation design considerations, 1st edn. Washington, DC, USA: API; 2011.

[2] International Standards Organisation. ISO19901-4: Petroleum and natural gas industries specific requirements for offshore structures - Part 4: Geotechnical and foundation design considerations, 1st edn. Geneva, Switzerland: ISO; 2003.

[3] European Committee for Standardization. Eurocode 7: Geotechnical design - Part 1: General rules. Brussels, Belgium: CEN; 2004.

[4] Gourvenec S. Shape effects on the capacity of rectangular footings under general loading. Géotechnique 2007;57(8):637-46.

[5] Bransby MF, Randolph MF. Combined loading of skirted foundations. Géotechnique 1998;48(5):637-55.

[6] Taiebat HA, Carter JP. Numerical studies of the bearing capacity of shallow foundations on cohesive soil subjected to combined loading. Géotechnique 2000;50(4):409-18.

[7] Gourvenec S, Randolph MF. Effect of strength non-homogeneity on the shape of failure envelopes for combined loading of strip and circular foundations on clay. Géotechnique 2003;53(6):575-86.

[8] Gourvenec S. Failure envelopes for offshore shallow foundations under general loading. Géotechnique 2007;57(9):715-28.

[9] Feng X, Randolph MF, Gourvenec S, Wallerand R. Design approach for rectangular mudmats under fully three-dimensional loading. Géotechnique 2014;64(1):51-63.

[10] Li X, Gaudin C, Tian Y, Cassidy MJ. Effect of perforations on uplift capacity of skirted foundations on clay. Can Geotech J 2013;51(3):322-31.

[11] Tapper L, Martin CM, Byrne BW. Undrained vertical bearing capacity of perforated offshore shallow foundations. In: Proceedings of the 3rd International Symposium on Frontiers in Offshore Geotechnics (ISFOG 2015), Oslo, Norway, 2015. p. 813-8.

[12] Mana DSK, Gourvenec S, Randolph MF. Experimental investigation of reverse end bearing of offshore shallow foundations. Can Geotech J 2013;50(10):1022-33.

[13] Meyerhof GG. The bearing capacity of foundations under eccentric and inclined loads. In: Proceedings of the 3rd International Conference on Soil Mechanics and Foundation Engineering, Zurich, Switzerland, vol.1; 1953. p. 440-5.

[14] Salençon J, Pecker A. Ultimate bearing capacity of shallow foundations under inclined and eccentric loads. I: Purely cohesive soil. Eur J Mech, A/Solids 1995;14(3):349-75.

[15] Drucker DC. A definition of a stable inelastic material. J Appl Mech 1959;26(1):101-6.

[16] Houlsby GT, Puzrin AM. The bearing capacity of a strip footing on clay under combined loading. Proc R Soc Lond Ser A 1999;455(1983):893-916.

[17] Ukritchon B, Whittle AJ, Sloan SW. Undrained limit analyses for combined loading of strip footings on clay. J Geotech Geoenviron Eng 1998;124(3):265-76.

[18] Taiebat HA, Carter JP. A failure surface for circular footings on cohesive soils. Géotechnique 2010;60(4):265-73.

[19] Bransby MF. Failure envelopes and plastic potentials for eccentrically loaded surface footings on undrained soil. Int J Numer Anal Methods Geomech 2001;25(4):329-46. 
[20] Dassault Systèmes. Abaqus analysis user’s manual. Simulia Corp, Providence, RI, USA; 2010.

[21] Butterfîeld R, Houlsby GT, Gottardi G. Standardized sign conventions and notation for generally loaded foundations. Géotechnique 1997;47(5):1051-4.

[22] Martin CM. New software for rigorous bearing capacity calculations. In: BGA International Conference on Foundations: innovations, observations, design and practice, Dundee, UK, 2003. p. 581-92.

[23] Taiebat HA, Carter JP. Flow rule effects in the Tresca model. Comput Geotech 2008;35(3):500-3.

[24] Tapper L, Martin CM, Byrne BW. Undrained bearing capacity of circular footings on Tresca soil using adaptive finite element analysis. In: Proceedings of the 8th International Conference on Numerical Methods in Geotechnical Engineering (NUMGE 2014), Delft, Netherlands, 2014. p. 699-704.

[25] Taiebat HA, Carter JP. Bearing capacity of strip and circular foundations on undrained clay subjected to eccentric loads. Géotechnique 2002;52(1):61-4.

[26] Green AP. The plastic yielding of metal junctions due to combined shear and pressure. J Mech Phys Solids 1954;2(3):197-211. 


\section{Table captions}

Table 1: Summary of notation for loads

Table 2: Comparison of dimensionless ultimate vertical load predicted in this study with published data

Table 3: Values of $M_{\mathrm{ult}} / A D s_{\mathrm{u} 0}$ and $v$ at $M_{\mathrm{ult}}$ predicted in this study with the traditional method 
Table 1: Summary of notation for loads

\begin{tabular}{llll}
\hline & Vertical & Horizontal & Moment \\
\hline Load & $V$ & $H$ & $M$ \\
Ultimate load & $V_{\text {ult }}$ & $H_{\text {ult }}$ & $M_{\mathrm{ult}}$ \\
Dimensionless load & $V / A s_{\mathrm{u} 0}$ & $H / A s_{\mathrm{u} 0}$ & $M / A D \mathrm{~s}_{\mathrm{u} 0}$ \\
Normalised load & $v=V / V_{\mathrm{ult}}$ & $h=H / H_{\mathrm{ult}}$ & $m=M / M_{\mathrm{ult}}$ \\
\hline
\end{tabular}

Table 2: Comparison of dimensionless ultimate vertical load predicted in this study with published data

\begin{tabular}{|c|c|c|c|c|c|}
\hline & & \multicolumn{4}{|c|}{$\kappa=k D / s_{\mathrm{u} 0}$} \\
\hline & & 0 & 2 & 6 & 10 \\
\hline \multirow{3}{*}{ Strip } & & 5.24 & 7.74 & 10.68 & 13.06 \\
\hline & 11IIS stuuy (FEA) & $(1.95 *)$ & $(1.84)$ & $(2.50)$ & (3.16) \\
\hline & Martin (2003) (MoC)** & 5.14 & 7.60 & 10.42 & 12.66 \\
\hline \multirow{3}{*}{ Circular } & Thin & 5.87 & 7.42 & 9.54 & 11.28 \\
\hline & $1111 \mathrm{~s}$ stuuy (ГLA) & $(-2.98)$ & $(-2.75)$ & $(-1.55)$ & $(-0.79)$ \\
\hline & Martin (2003) (MoC) & 6.05 & 7.63 & 9.69 & 11.37 \\
\hline
\end{tabular}

* Percentage of difference from analytical solutions

** Method of characteristics

Table 3: Values of $M_{\mathrm{ult}} / A D s_{\mathrm{u} 0}$ and $v$ at $M_{\mathrm{ult}}$ predicted in this study with the traditional method

\begin{tabular}{llllll}
\hline \multirow{2}{*}{ Strip } & & \multicolumn{3}{c}{$\kappa=k D / s_{\mathrm{u} 0}$} \\
& This study (FEA), $M_{\mathrm{ult}} / A D s_{\mathrm{u}}$ & 0.674 & 0.861 & 1.111 & 1.313 \\
& Value of $v$ at $M_{\mathrm{ult}}$ & 0.51 & 0.48 & 0.47 & 0.47 \\
& Traditional method, $M_{\mathrm{ult}} / A D s_{\mathrm{u}}$ & 0.643 & 0.820 & 1.074 & 1.264 \\
& Value of $v$ at $M_{\mathrm{ult}}$ & 0.50 & 0.47 & 0.47 & 0.46 \\
\hline \multirow{3}{*}{ Circular } & This study (FEA), $M_{\mathrm{ult}} / A D s_{\mathrm{u}}$ & 0.605 & 0.723 & 0.892 & 1.033 \\
& Value of $v$ at $M_{\mathrm{ult}}$ & 0.49 & 0.48 & 0.47 & 0.48 \\
& Traditional method, $M_{\mathrm{ult}} / A D s_{\mathrm{u}}$ & 0.580 & 0.692 & 0.868 & 0.999 \\
& Value of $v$ at $M_{\mathrm{ult}}$ & 0.47 & 0.47 & 0.47 & 0.46 \\
\hline
\end{tabular}




\section{Figure captions}

Figure 1: Failure envelopes for strip and circular foundations with zero-tension interface on uniform soil $\left(V / V_{\text {ult }}=0.5\right)$

Figure 2: Finite element mesh for circular foundation

Figure 3: Notation and sign convention for foundation and soil conditions

Figure 4: Representation of behaviour of zero-tension soil-foundation interface

Figure 5: Flowchart of UNITER for simulating ideal zero-tension interface

Figure 6: Failure envelopes for strip foundations with zero-tension interface on uniform soil

Figure 7: Failure envelopes for circular foundations with zero-tension interface on uniform soil

Figure 8: Failure envelopes for foundations for V-H loading

Figure 9: Failure envelopes for strip foundations for V-M loading

Figure 10: Failure envelopes for circular foundations for V-M loading

Figure 11: Normalised vertical bearing capacity of foundations under an eccentric vertical load

Figure 12: Failure envelopes for strip foundations for V-H-M loading

Figure 13: Failure envelopes for circular foundations for V-H-M loading

Figure 14: Non-linear VM coupling at high vertical load mobilisation and low strength heterogeneity

Figure 15: Interface status for strip foundations on uniform soil under combined V-H-M loading 


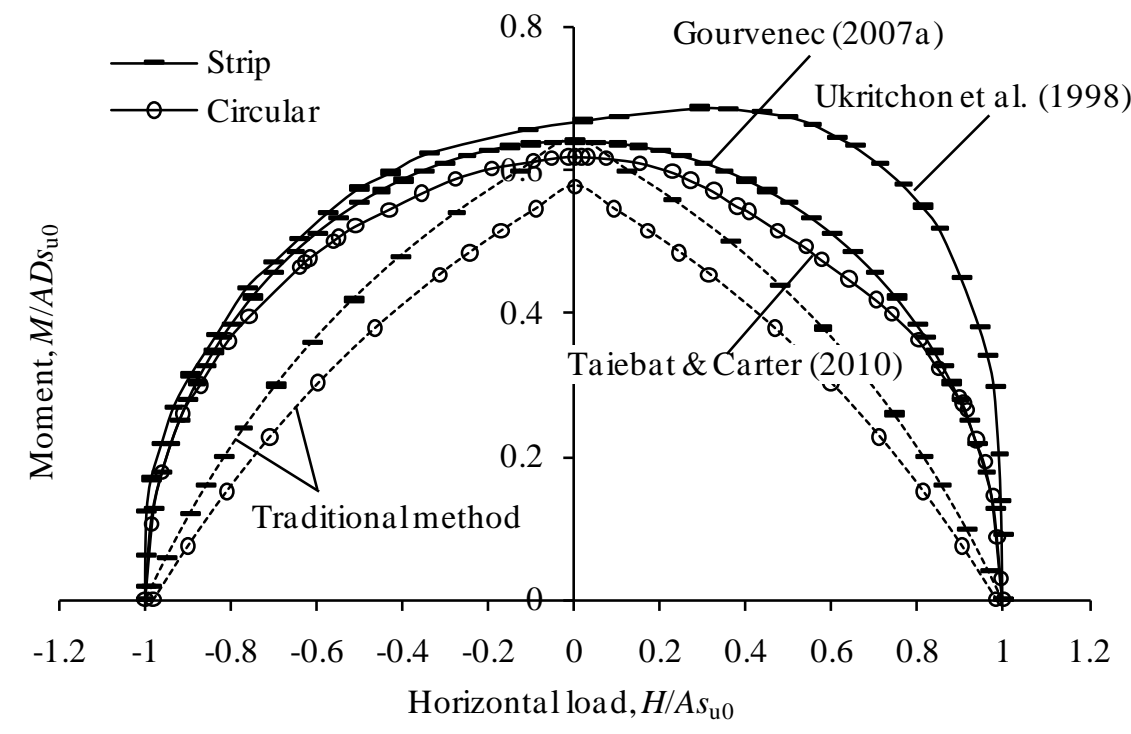

Figure 1: Failure envelopes for strip and circular foundations with zero-tension interface on uniform soil $\left(V / V_{\text {ult }}=0.5\right)$

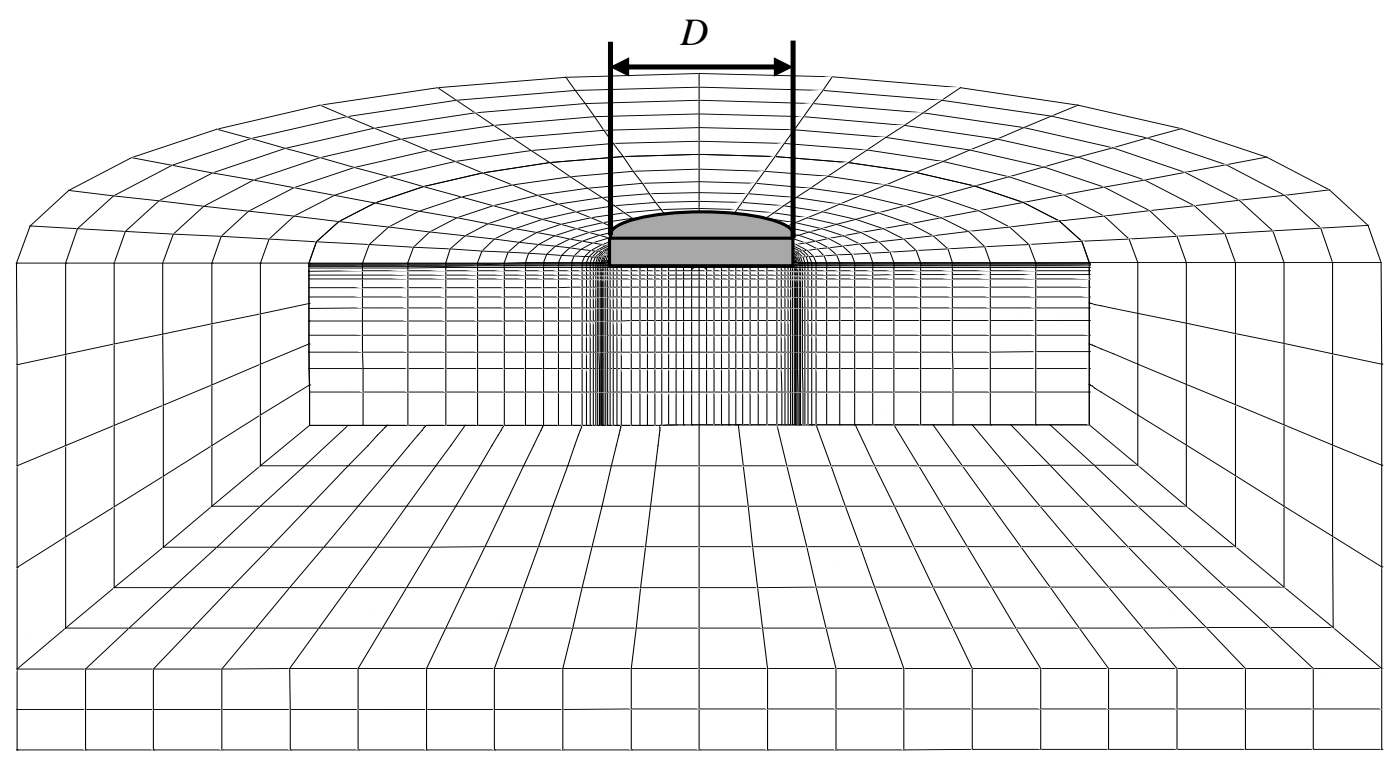

Figure 2: Finite element mesh for circular foundation 

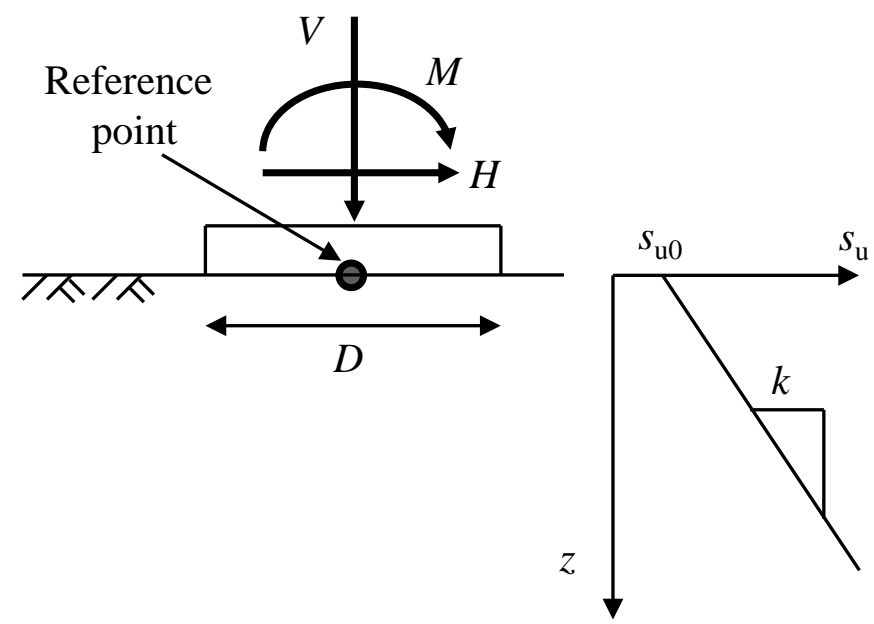

Figure 3: Notation and sign convention for foundation and soil conditions

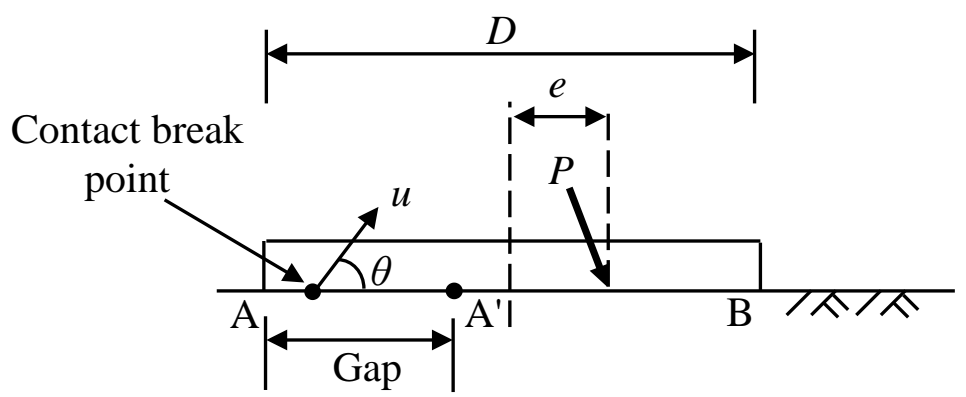

(a) notation for response of detaching foundation

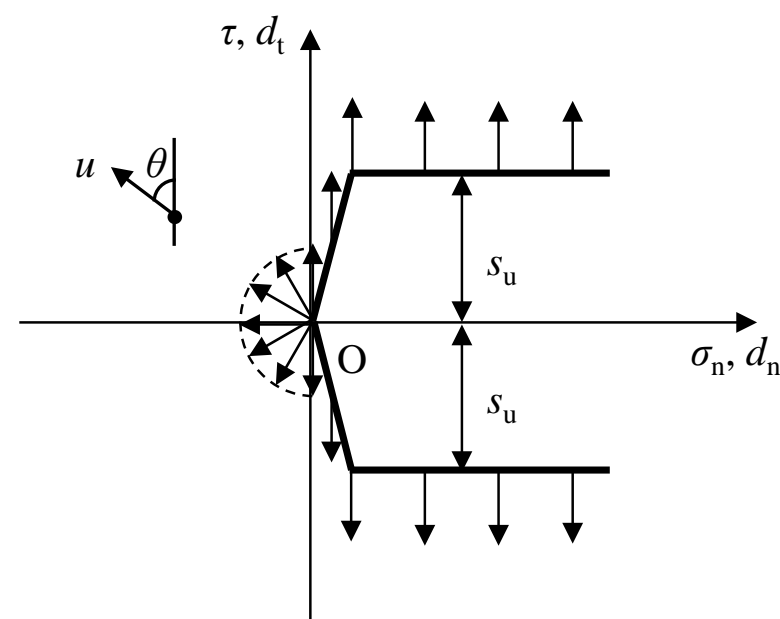

(b) Coulomb friction, friction angle, $\varphi$, approaching $90^{\circ}\left(87.1^{\circ}\right)$

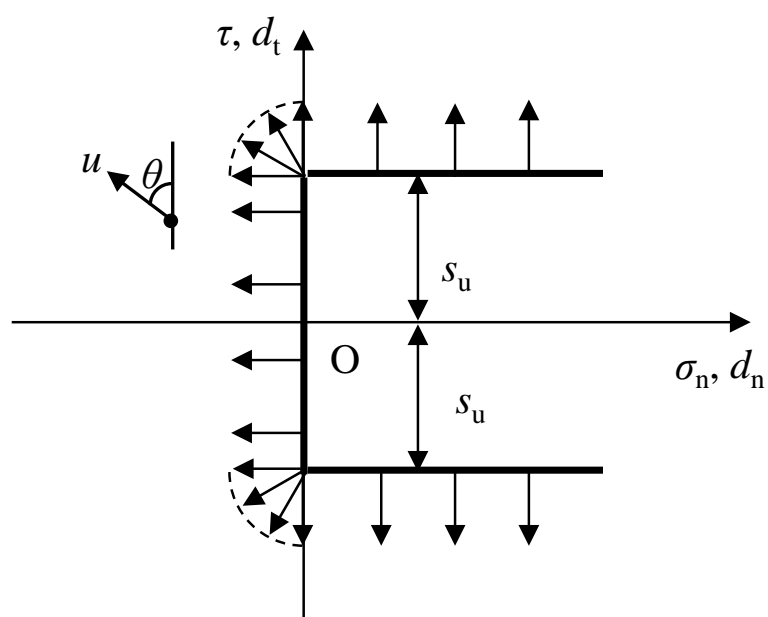

(c) ideal zero-tension interface

Figure 4: Representation of behaviour of zero-tension soil-foundation interface 


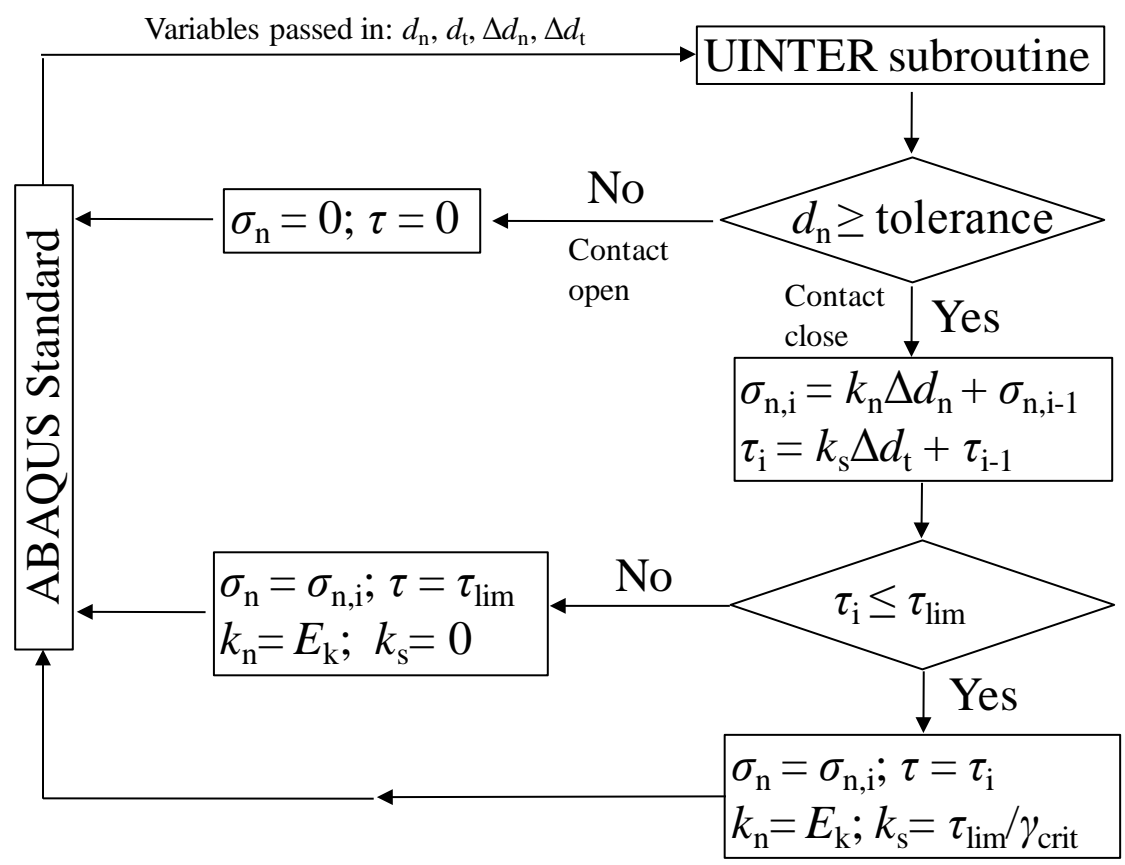

Figure 5: Flowchart of UNITER for simulating ideal zero-tension interface

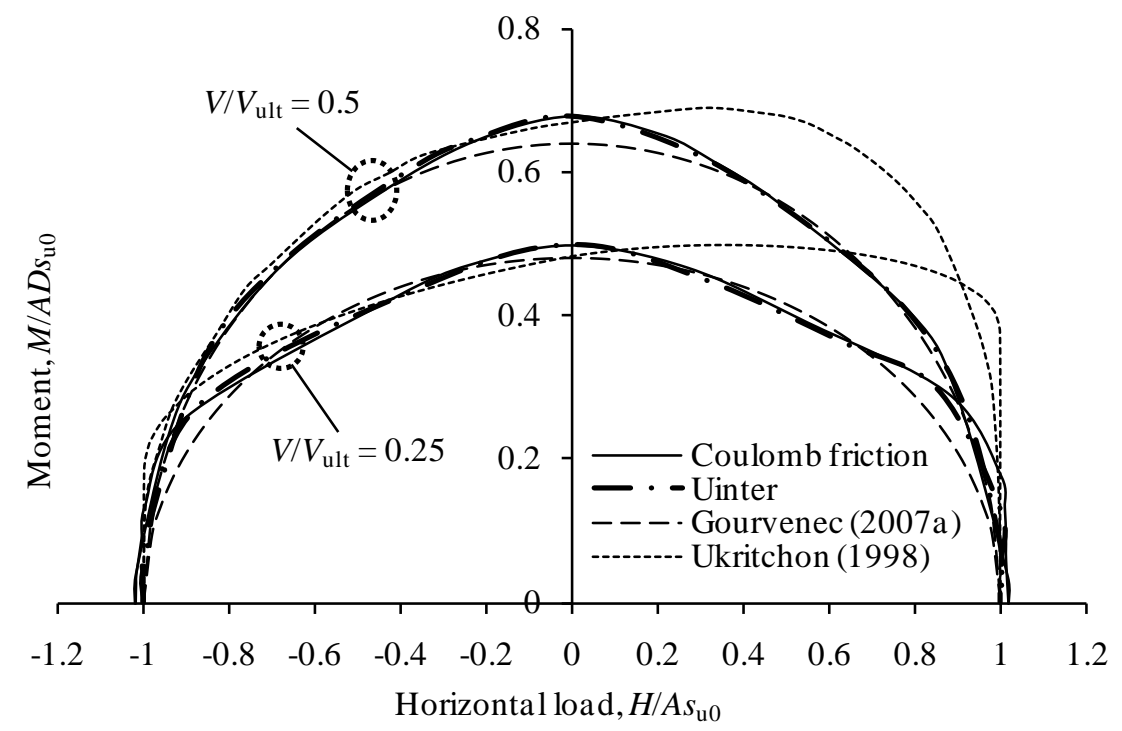

Figure 6: Failure envelopes for strip foundations with zero-tension interface on uniform soil 


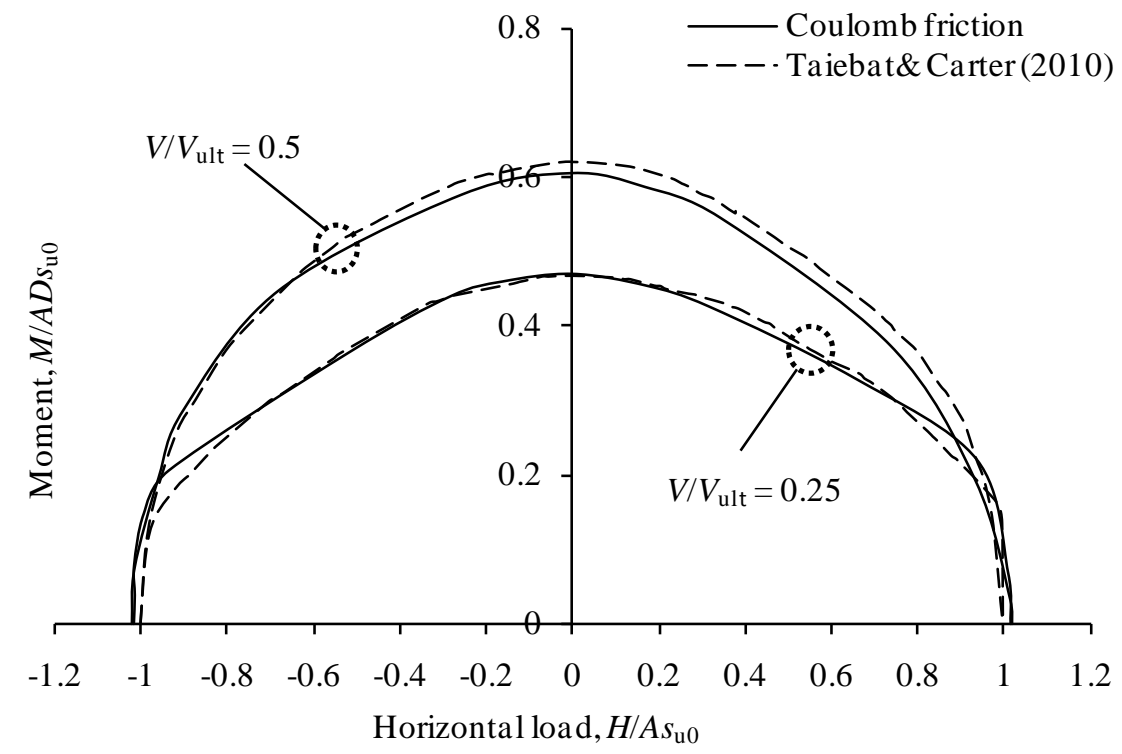

Figure 7: Failure envelopes for circular foundations with zero-tension interface on uniform soil

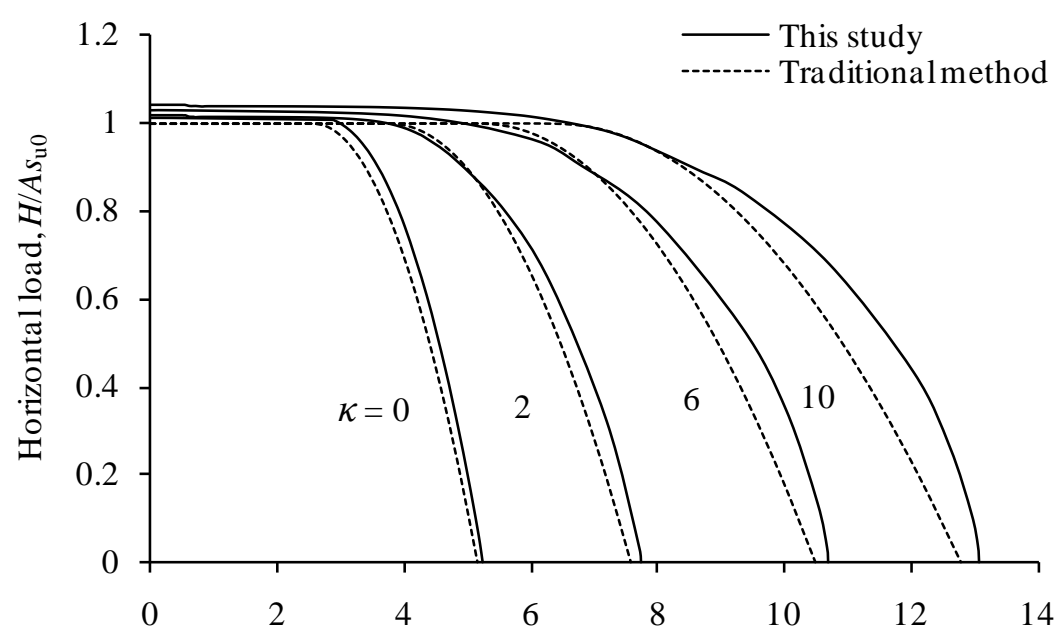

Vertical load, $V / A s_{\mathrm{u} 0}$

(a) strip foundations 


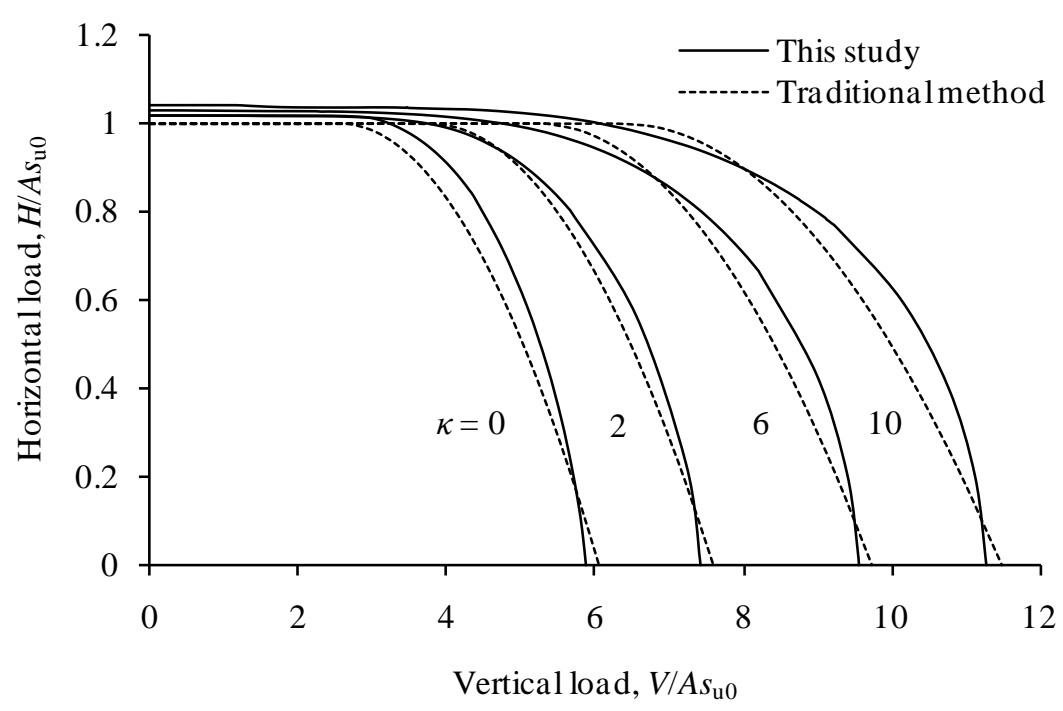

(b) circular foundations

Figure 8: Failure envelopes for foundations for V-H loading

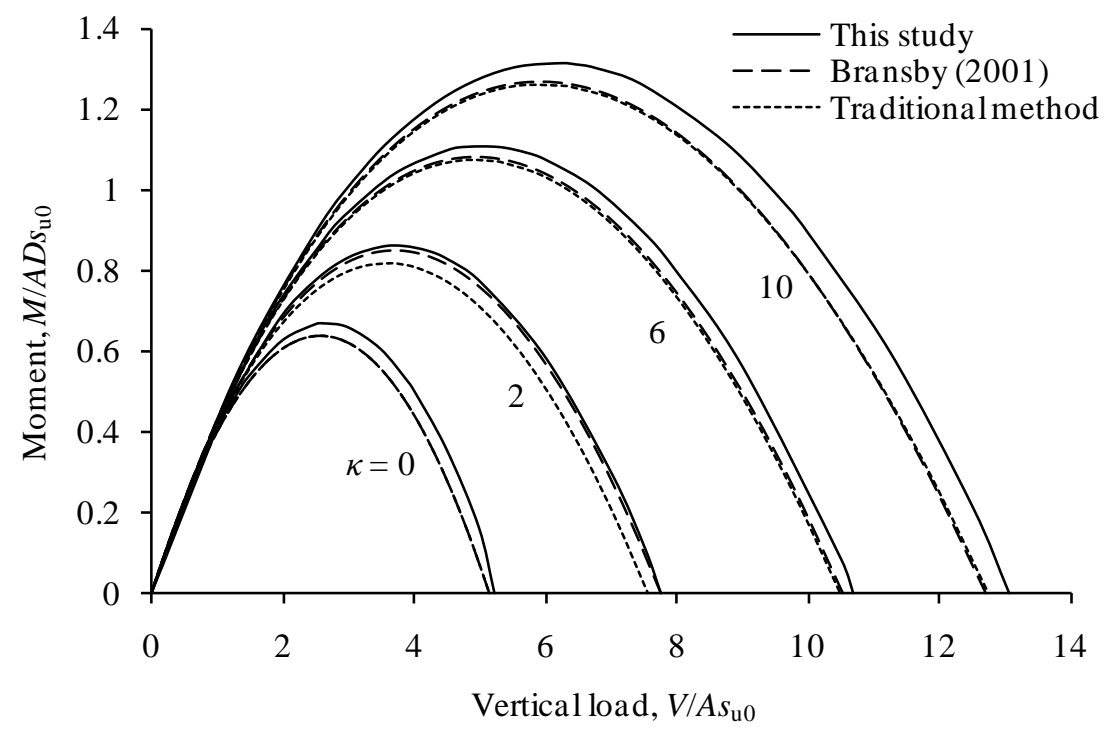

(a) dimensionless load space 


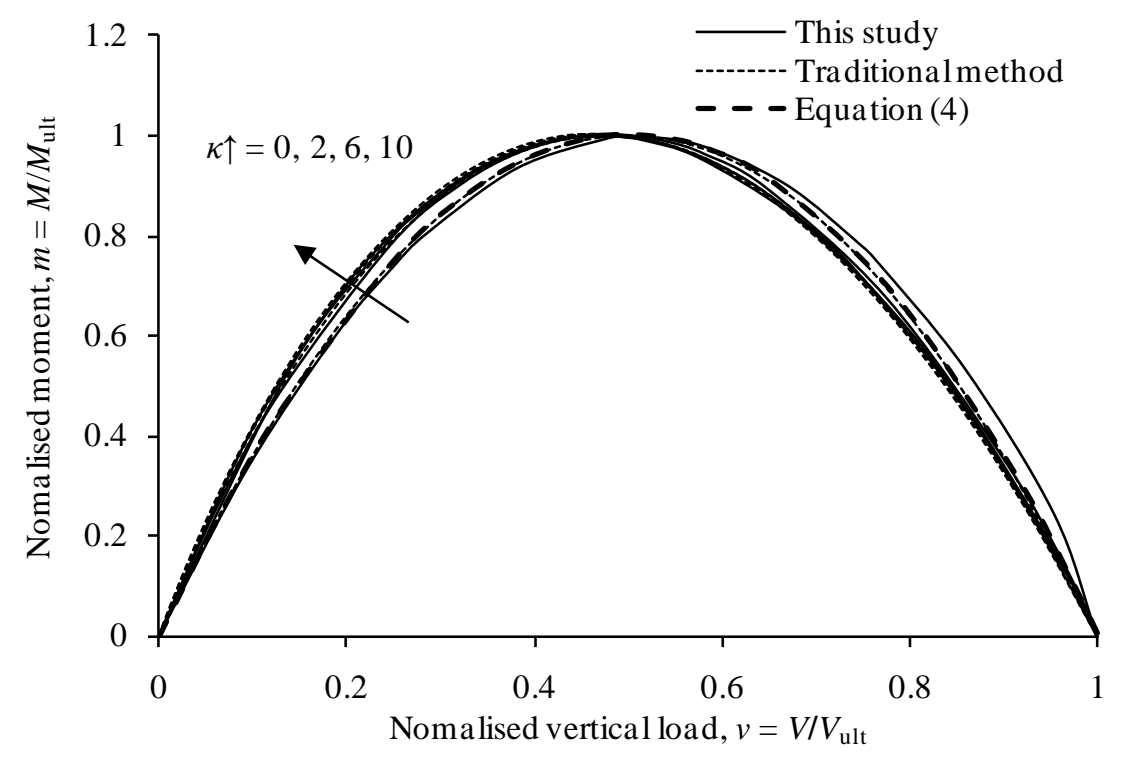

(b) normalised load space

Figure 9: Failure envelopes for strip foundations for V-M loading

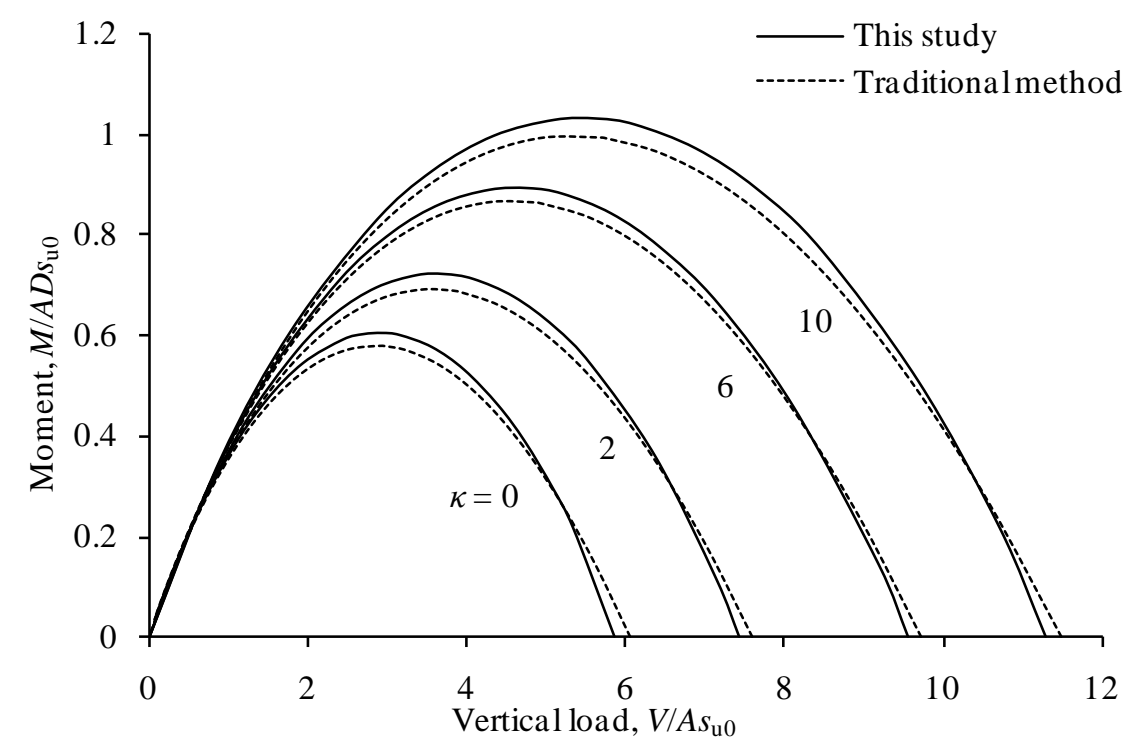

(a) dimensionless load space 


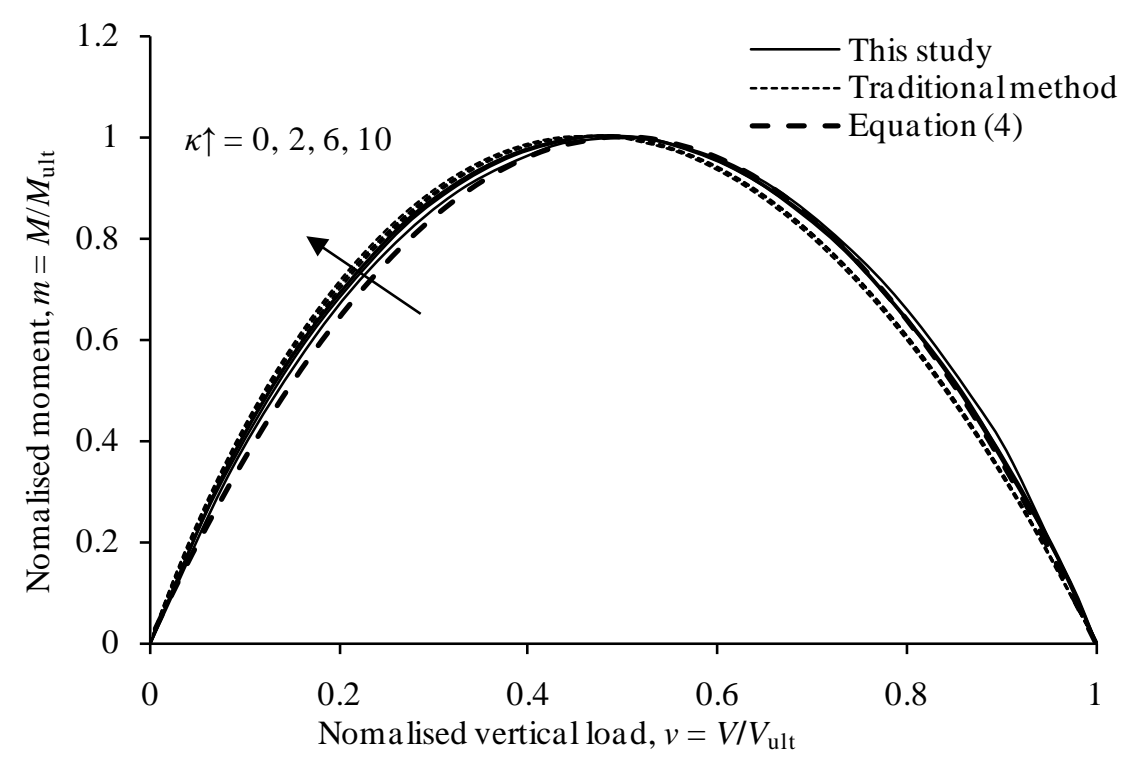

(b) normalised load space

Figure 10: Failure envelopes for circular foundations for V-M loading

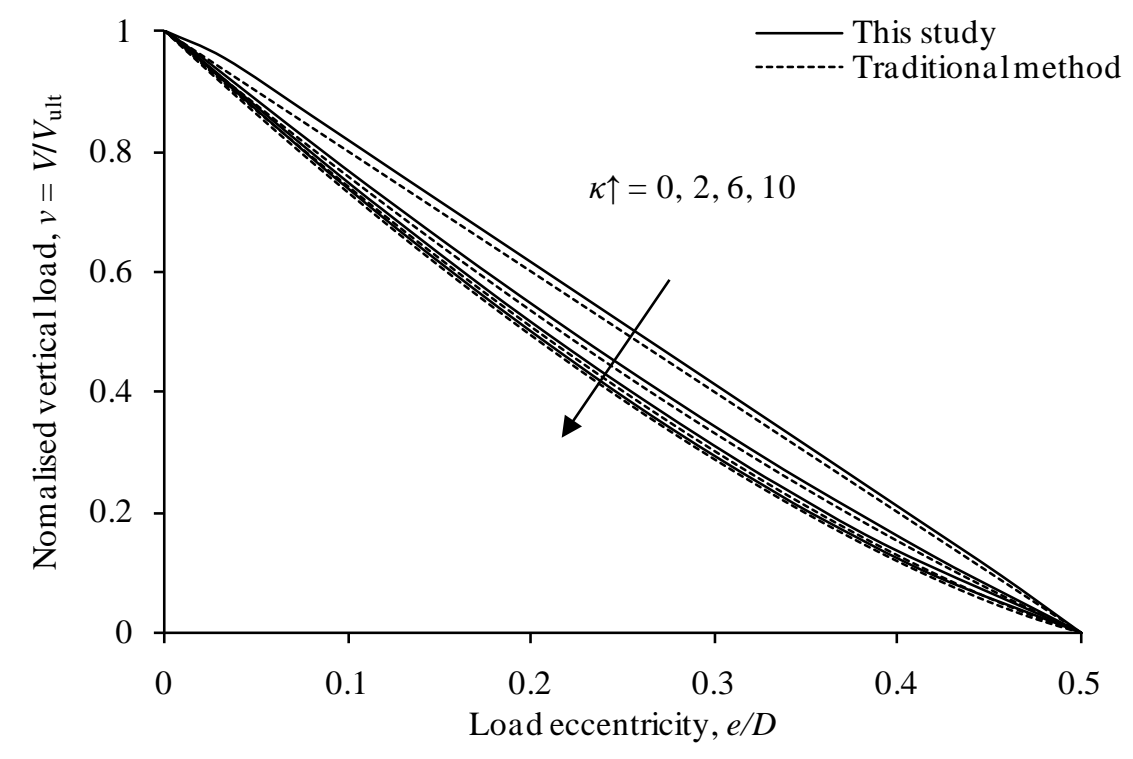

(a) strip foundations 


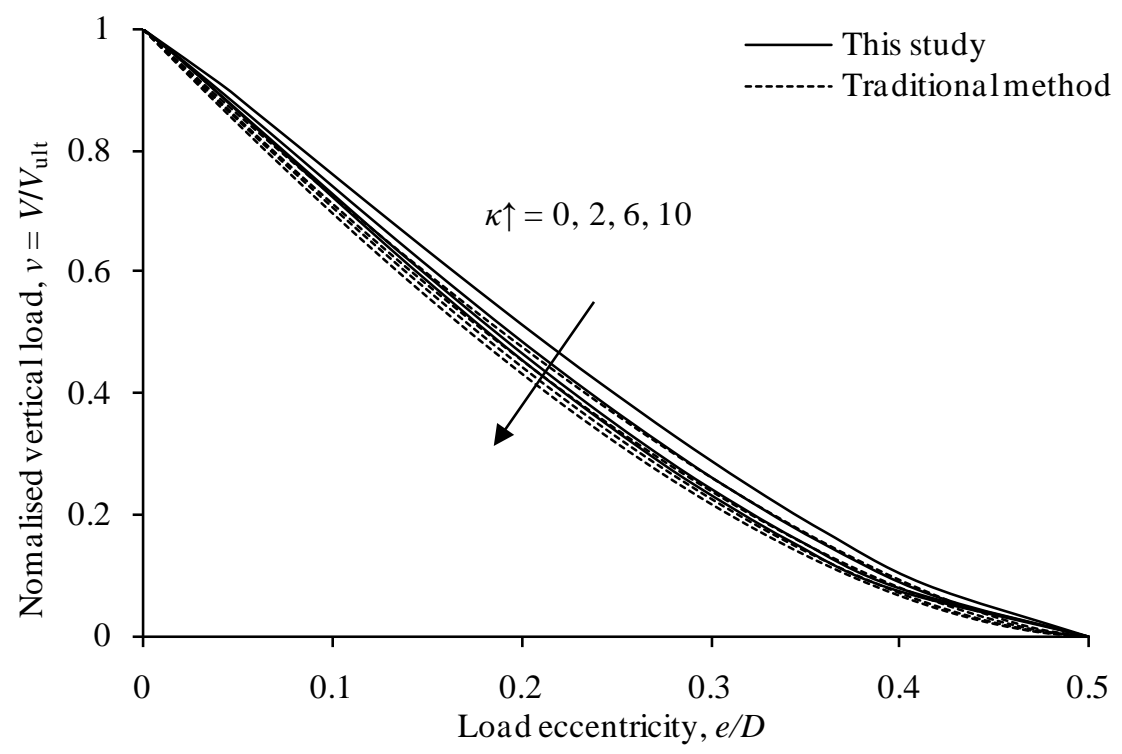

(b) circular foundations

Figure 11: Normalised vertical bearing capacity of foundations under an eccentric vertical load 


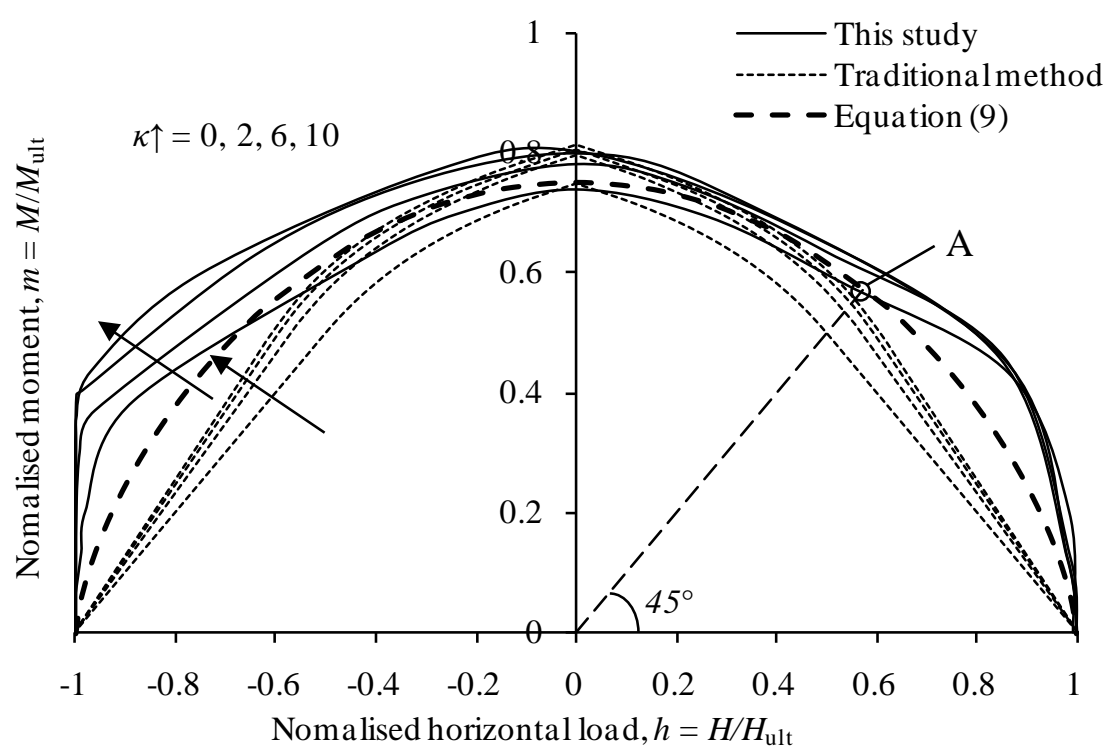

(a) $V / V_{\text {ult }}=0.25$

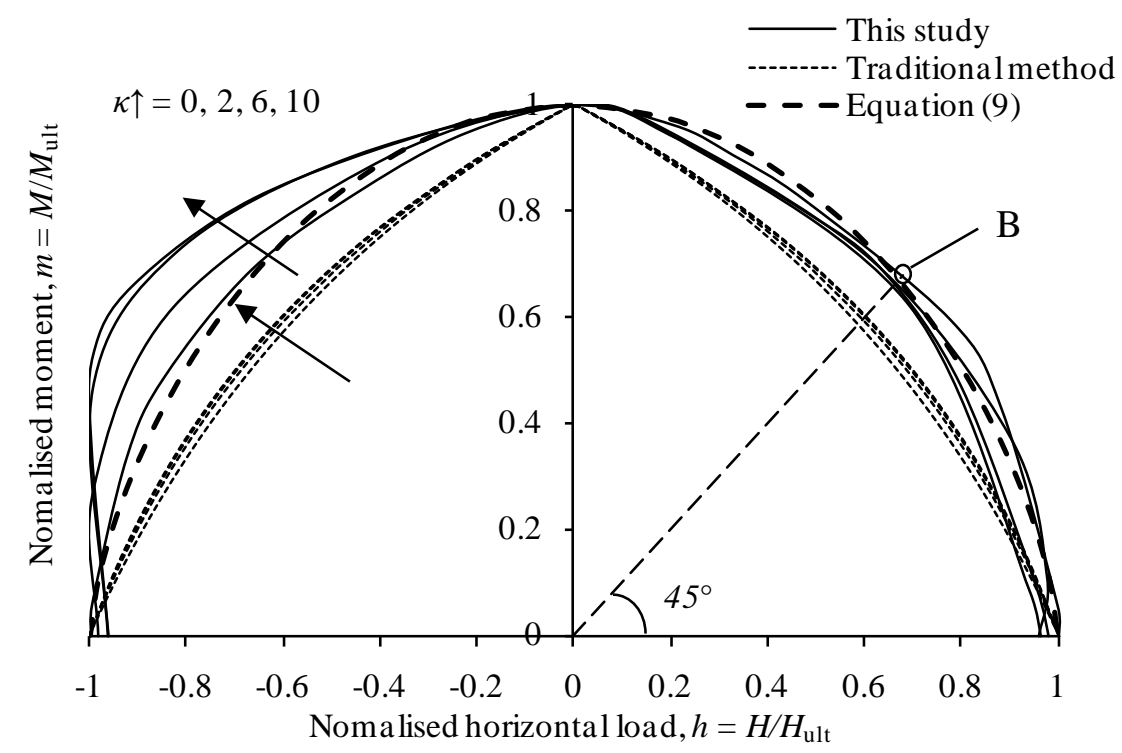

(b) $V / V_{\text {ult }}=0.5$ 


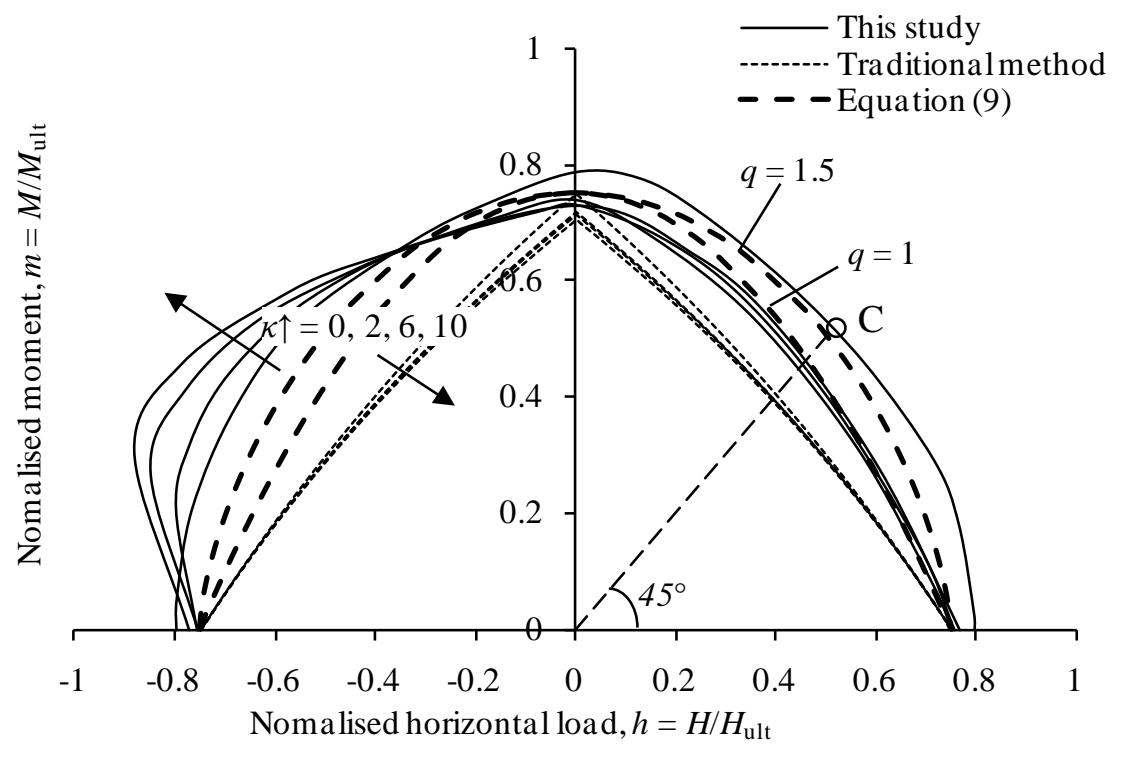

(c) $V / V_{\text {ult }}=0.75$

Figure 12: Failure envelopes for strip foundations for V-H-M loading

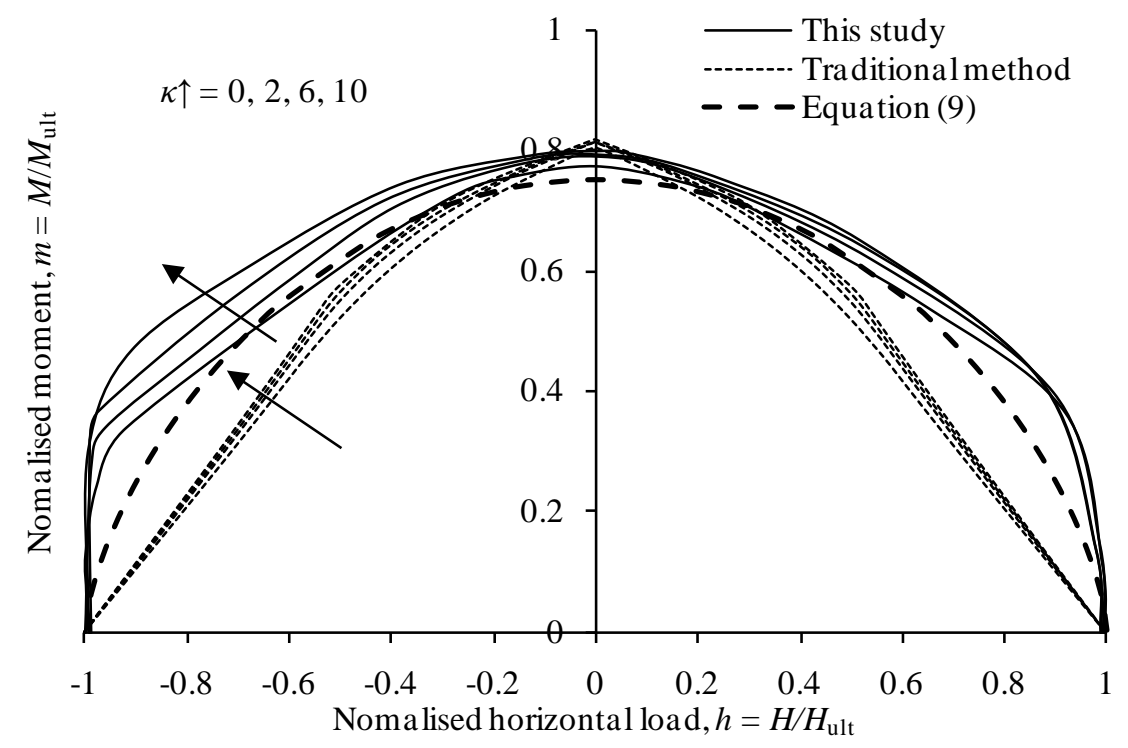

(a) $V / V_{\text {ult }}=0.25$ 


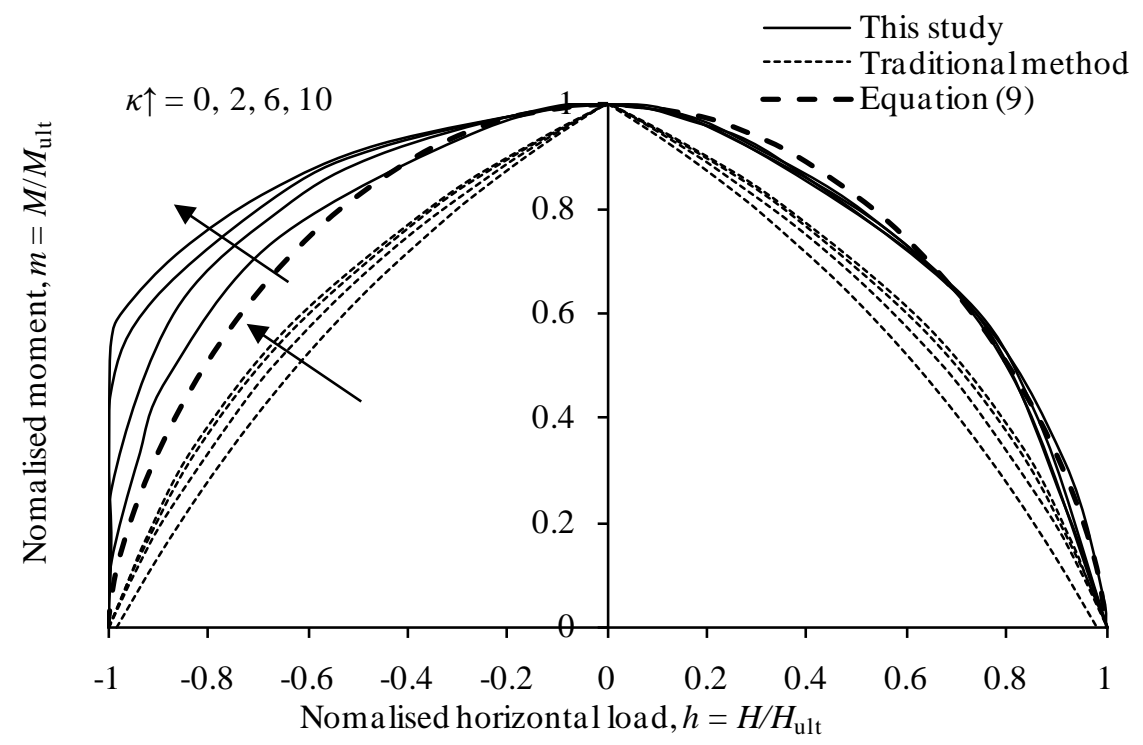

(b) $V / V_{\text {ult }}=0.5$

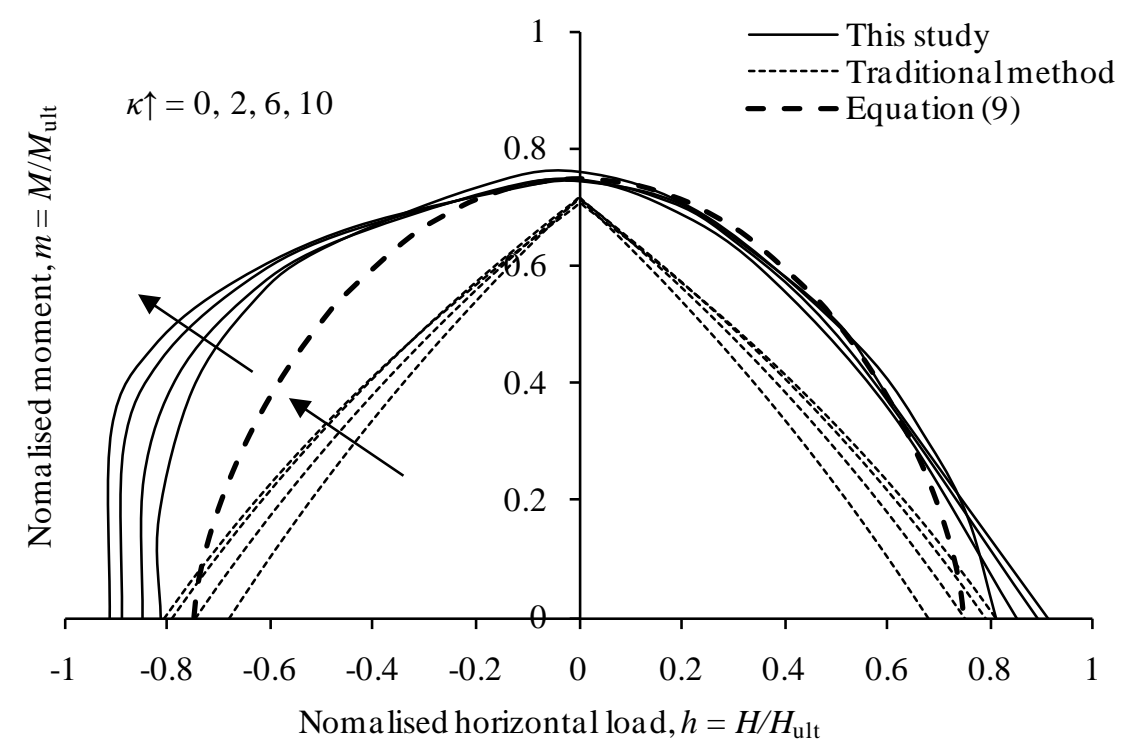

(c) $V / V_{\text {ult }}=0.75$

Figure 13: Failure envelopes for circular foundations for V-H-M loading 


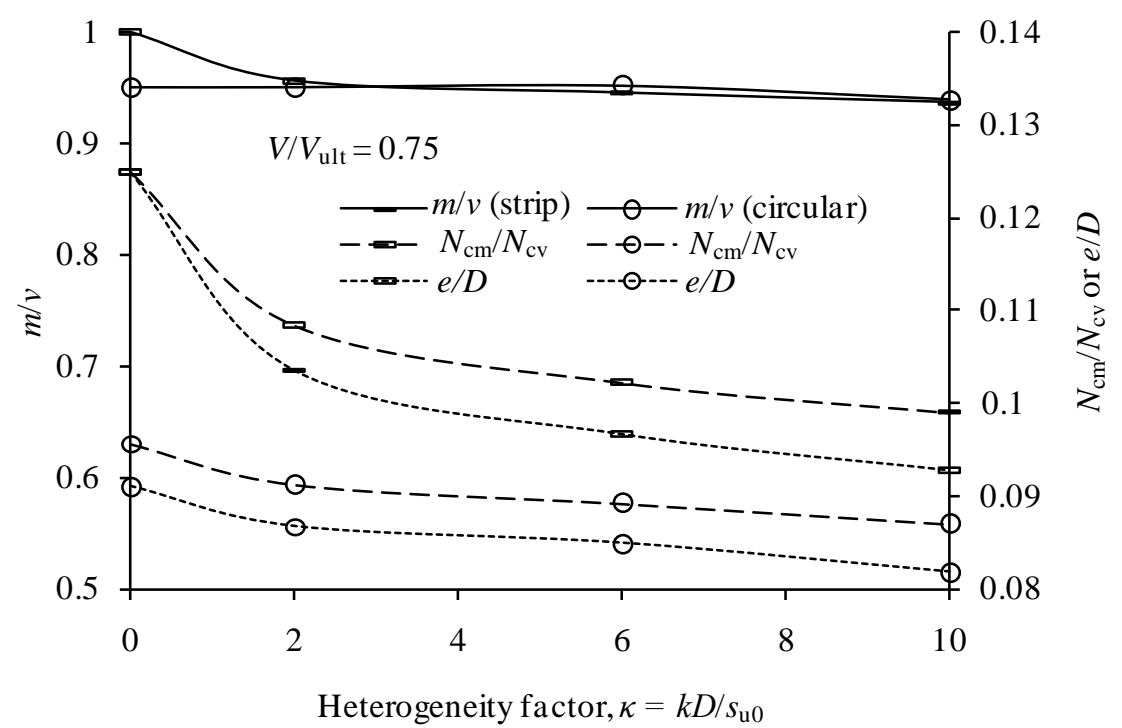

Figure 14: Non-linear VM coupling at high vertical load mobilisation and low strength heterogeneity 


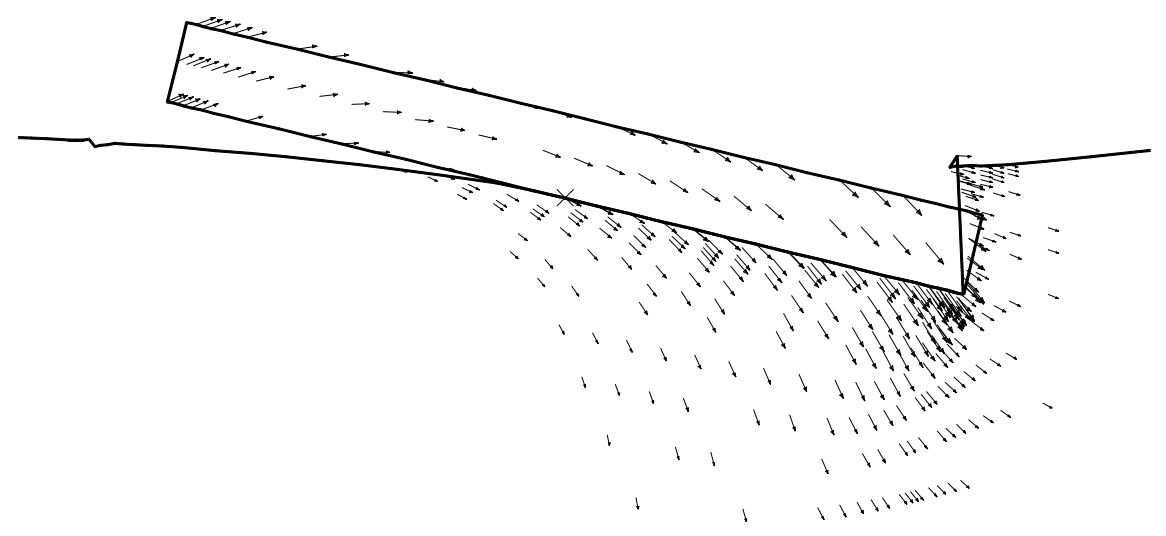

(a) $V / V_{\text {ult }}=0.25$ (scaling factor: 100 )

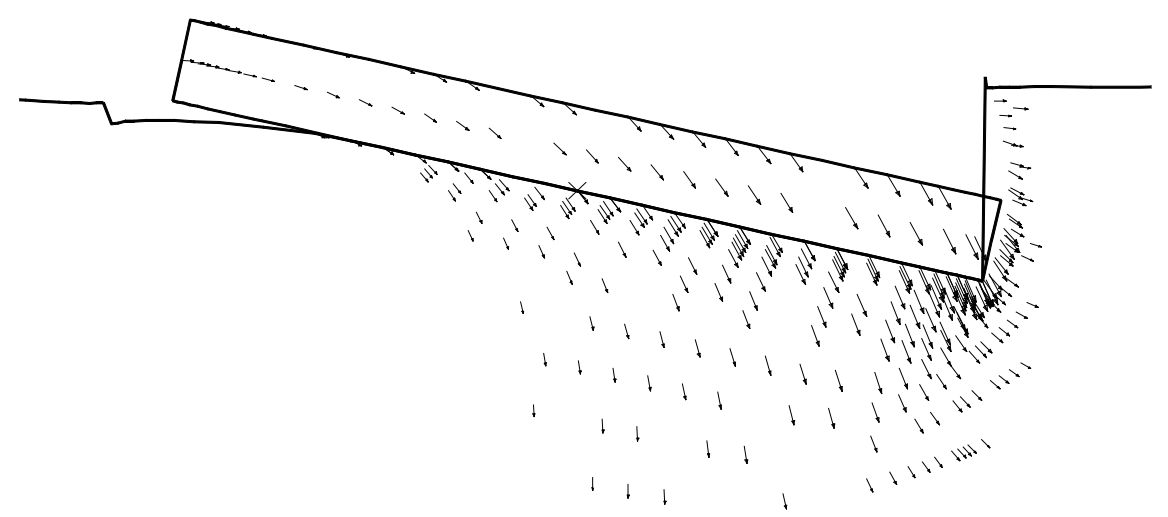

(b) $V / V_{\text {ult }}=0.5$ (scaling factor: 50 )

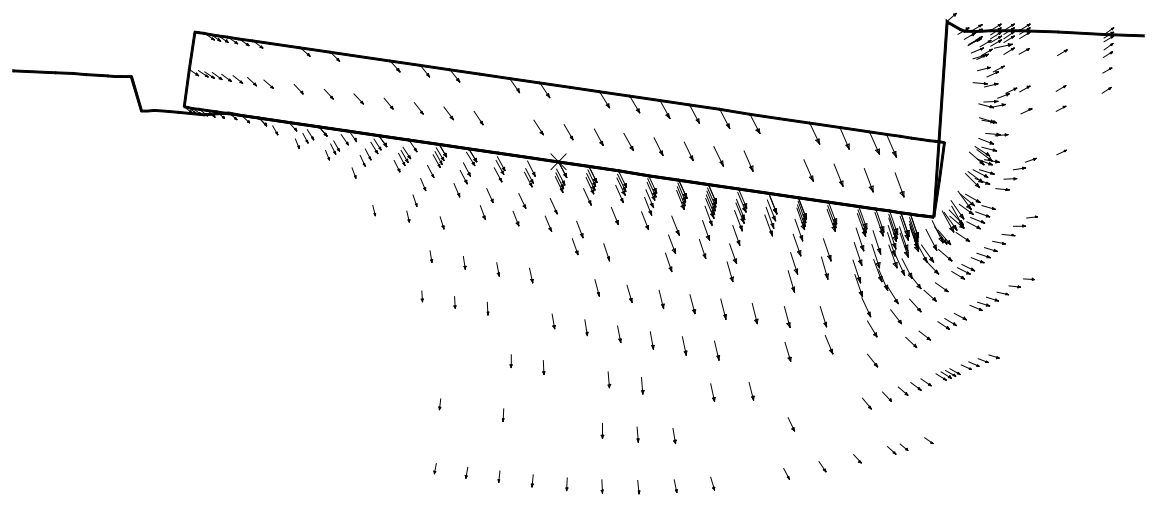

(c) $V / V_{\text {ult }}=0.75$ (scaling factor: 20 )

Figure 15: Interface status for strip foundations on uniform soil under combined V-H-M loading 